OAK RIDGE

NATIONAL LABORATORY MANAGED BY UT-BATTELLE

FOR THE DEPARTMENT OF ENERGY
ORNL/TM-2000/86

\title{
Transportation Routing Analysis Geographic Information System (WebTRAGIS) User's Manual
}

P. E. Johnson

R. D. Michelhaugh

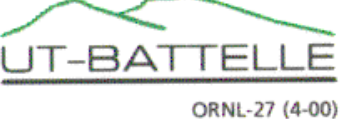




\section{DOCUMENT AVAILABILITY}

Available electronically from the following source:

Web site www.doe.gov/bridge

Reports are available in paper to the public from the following source.

National Technical Information Service

5285 Port Royal Road

Springfield, VA 22161

Telephone 1-800-553-6847

TDD 703-487-4639

Fax 703-605-6900

E-mail orders@ntis.fedworld.gov

Web site www.ntis.gov/ordering.htm

Reports are available in paper to U.S. Department of Energy (DOE) employees, DOE contractors, Energy Technology Data Exchange (ETDE) representatives, and International Nuclear Information System (INIS) representatives from the following source.

Office of Scientific and Technical Information

P.O. Box 62

Oak Ridge, TN 37831

Telephone 865-576-8401

Fax 865-576-5728

E-mail reports@adonis.osti.gov

Web site http://www.osti.gov/contact.html

This report was prepared as an account of work sponsored by an agency of the United States Government. Neither the United States Government nor any agency thereof, nor any of their employees, making any warranty, express or implied, or assumes any legal liability or responsibility for the accuracy, completeness, or usefulness of any information, apparatus, product, or process disclosed, or represents that its use would not infringe privately owned rights. References herein to any specific commercial product, process, or service by trade name, trademark, manufacturer, or otherwise, does not necessarily constitute or imply its endorsement, recommendation, or favoring by the United States Government or any agency thereof. The views and opinions of authors expressed herein do not necessarily state or reflect those of the United States Government or any agency thereof. 


\title{
Transportation Routing Analysis Geographic Information System (WebTRAGIS) User's Manual
}

\author{
P. E. Johnson* \\ R. D. Michelhaugh \\ ${ }^{*}$ Computational Physics and Engineering Division
}

April 2000

\begin{abstract}
Prepared for the
National Transportation Program

U.S. Department of Energy

Albuquerque, New Mexico 87185
\end{abstract}

Prepared by the OAK RIDGE NATIONAL LABORATORY

Oak Ridge, Tennessee 37831-6495

managed by

UT-Battelle, LLC

for the

U.S. DEPARTMENT OF ENERGY

under contract DE-AC05-00OR22725 
Page intentionally left blank 


\section{CONTENTS}

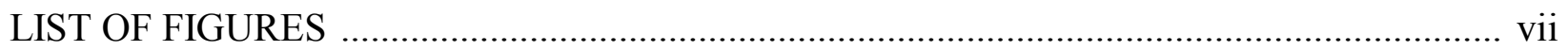

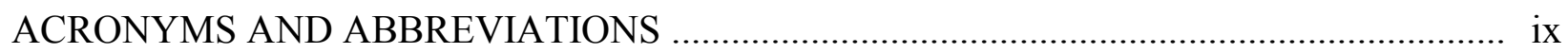

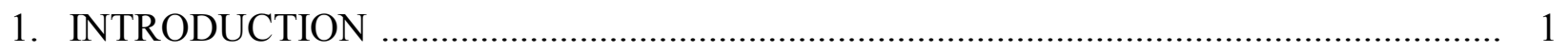

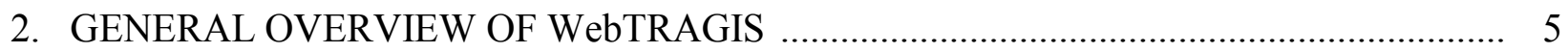

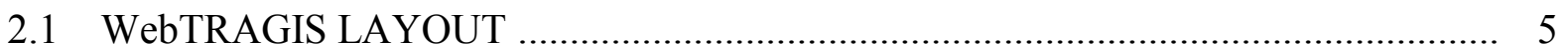

2.1.1 Tab 1-Select Origin/Destination ............................................................... 6

2.1.2 Tab 2-Optional Highway Routing Parameters............................................... 6

2.1.3 Tab 3-Optional Rail/Water Routing Parameters ………………………....... 6

2.1.4 Tab 4-Block Nodes/Links ........................................................................ 7

2.1.5 Tab 5-Route Listings ………………………........................................... 7

2.1.6 Tab 6-Route Maps ................................................................................... 7

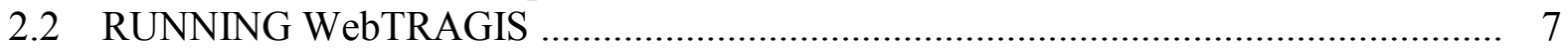

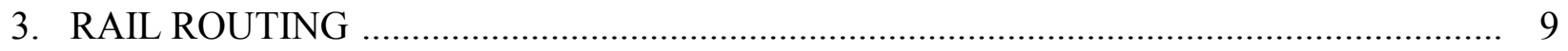

3.1 SELECT ORIGIN/DESTINATION TAB ………............................................. 9

3.1.1 Selecting Origin ................................................................................. 9

3.1.2 Selecting Destination ............................................................................... 10

3.1.3 Routing Options ……………........................................................... 10

3.1.4 Calculate Route and Calculate Alternative Route .......................................... 11

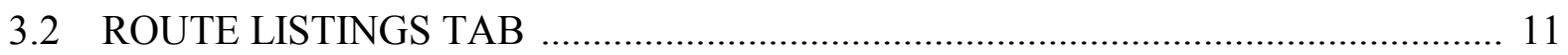

3.3 OPTIONAL RAIL/WATER ROUTING PARAMETERS TAB ………………......... 12

3.3.1 Rail Line Type Weighting ............................................................................ 13

3.3.2 Originating Railroad Preference ……………................................................ 13

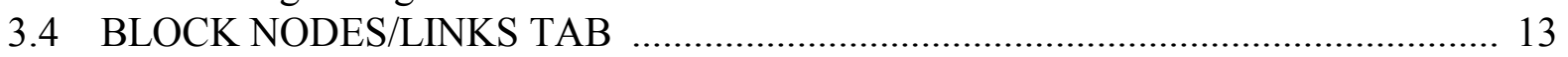

3.4.1 Node Blocking .................................................................................. 14

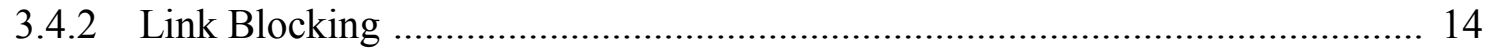

3.4.3 Block Railroad Company ………………….............................................. 15

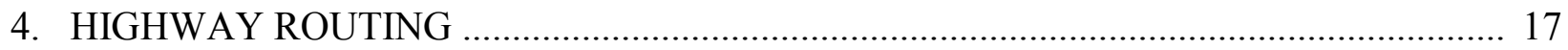

4.1 SELECT ORIGIN/DESTINATION TAB ………............................................ 18

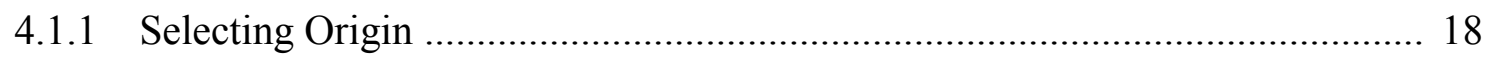

4.1.2 Selecting Destination ................................................................................ 18

4.1.3 Routing Options ……………........................................................... 18

4.1.4 Calculate Route and Calculate Alternative Route ........................................ 18

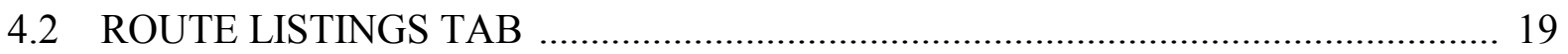

4.3 OPTIONAL HIGHWAY ROUTING PARAMETERS TAB …………………......... 21

4.3.1 Driver Options .................................................................................... 21

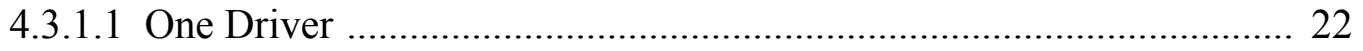

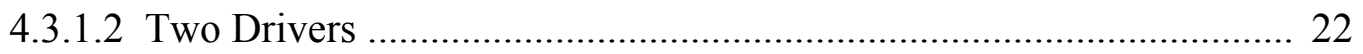




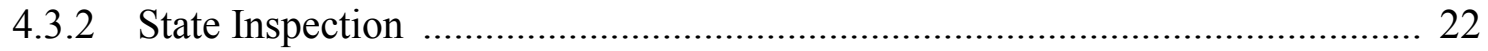

4.3.3 Date/Time Options …………………………....................................... 23

4.3.4 Other Routing Constraints ......................................................................... 23

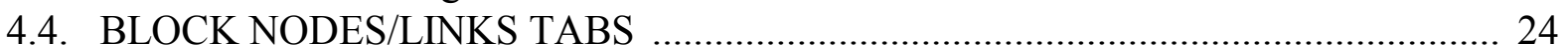

4.4.1 Node Blocking ................................................................................... 24

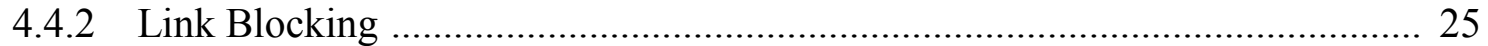

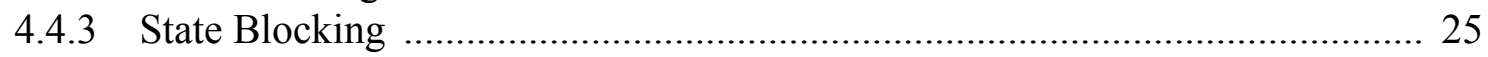

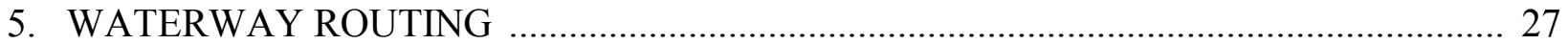

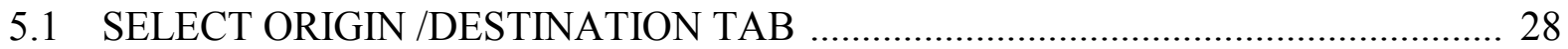

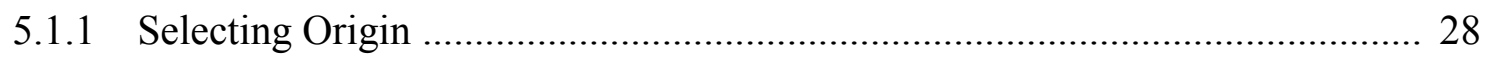

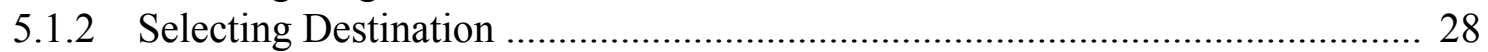

5.1.3 Calculate Route and Calculate Alternative Route …………………….......... 28

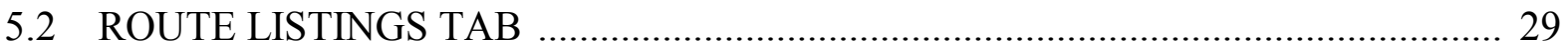

5.3 OPTIONAL RAIL/WATER ROUTING PARAMETERS TAB ……......................... 30

5.3.1 Select Water Route Type ……………………......................................... 30

5.3.2 Modify Mode Transfer Penalty ............................................................... 30

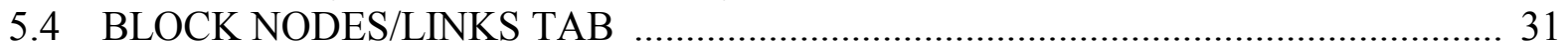

5.4.1 Node Blocking .......................................................................................... 31

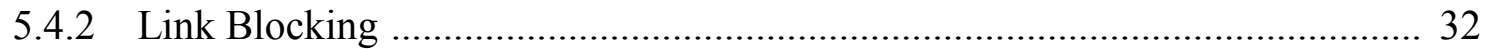

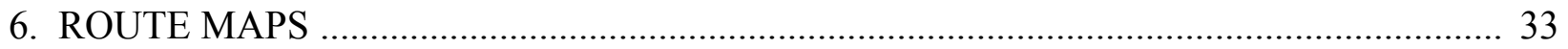

6.1 BUTTON BAR ITEMS ON ROUTE MAPS TAB ……………......................... 33

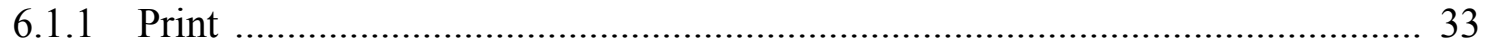

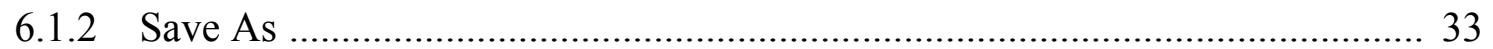

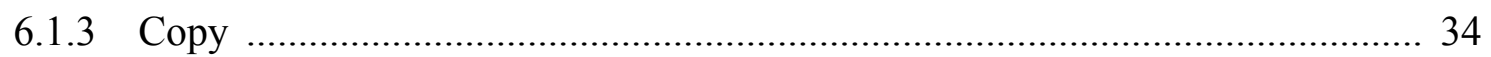

6.1.4 Map Properties ................................................................................. 34

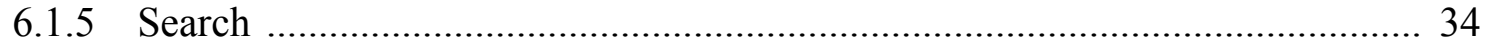

6.1.6 Display Full Extent of Map ........................................................................ 34

6.1.7 Display Map to Extent of Active Layer …………............................................. 34

6.1.8 Add Map Layer .................................................................................... 34

6.1.9 Remove Active Map Layer ………………............................................ 34

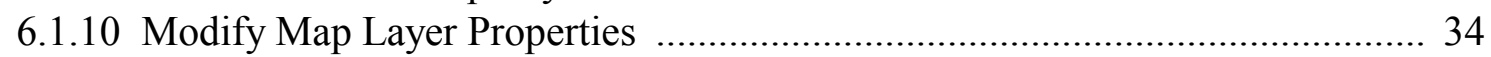

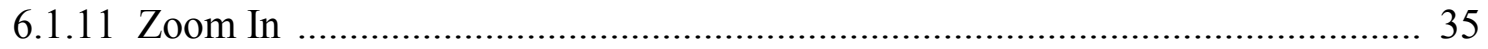

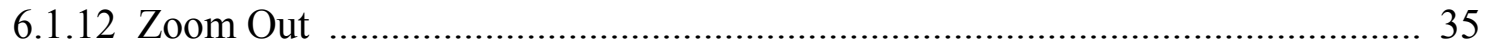

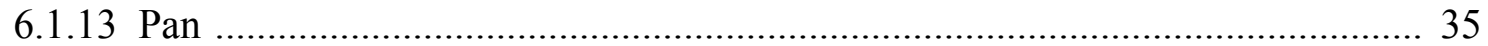

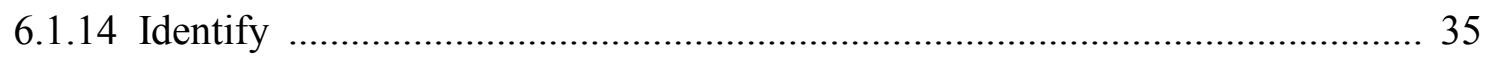

6.1.15 Add Graphics to Map …………………................................................. 35

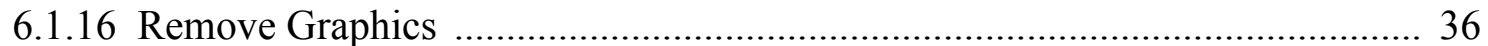

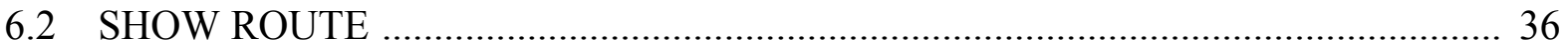

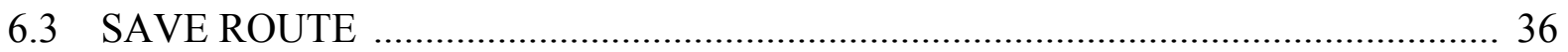

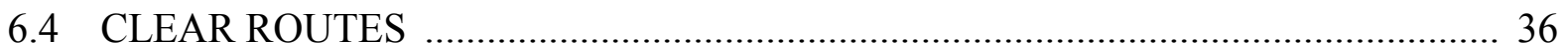

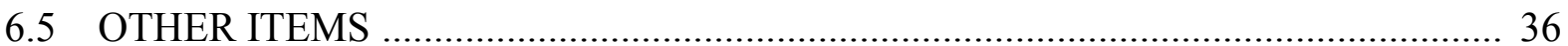




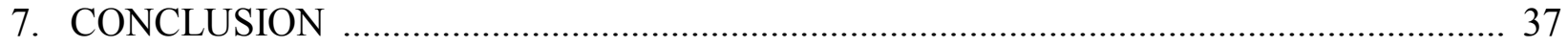

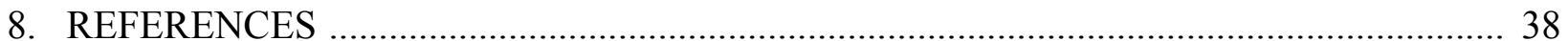


Page intentionally left blank 


\section{LIST OF FIGURES}

Figure

Page

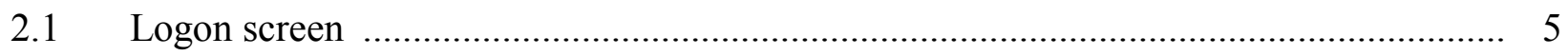

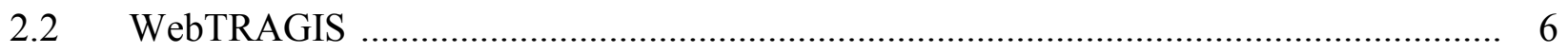

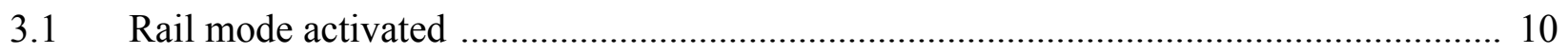

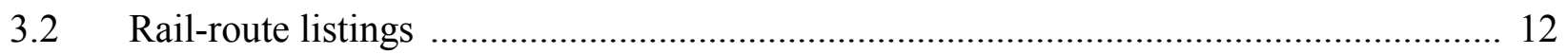

3.3 Optional rail-routing parameters ……………........................................................ 13

$3.4 \quad$ Rail node/link blocking .................................................................................. 14

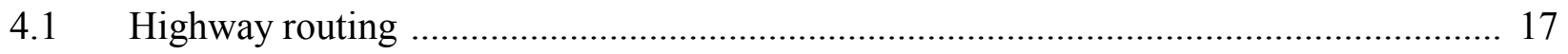

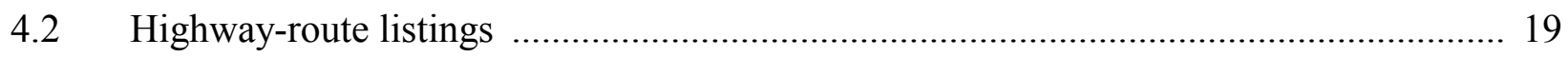

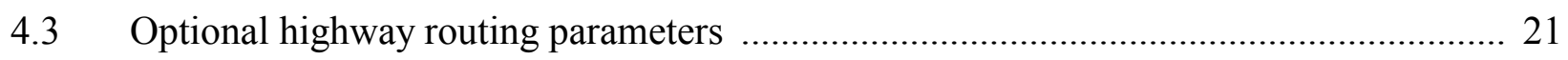

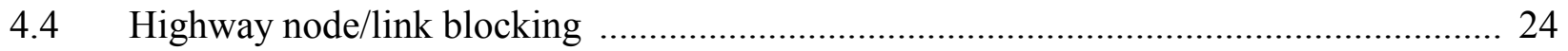

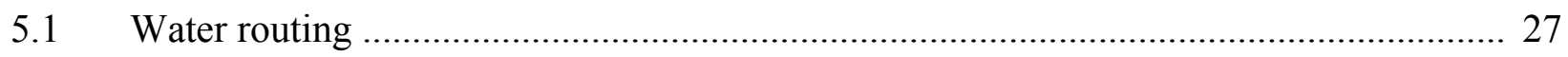

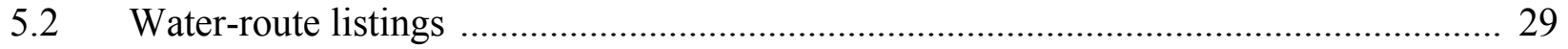

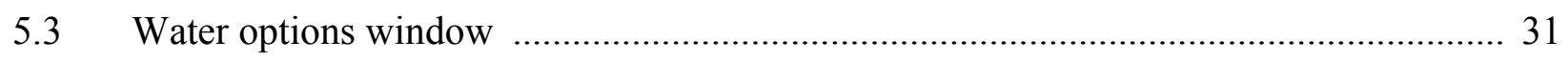

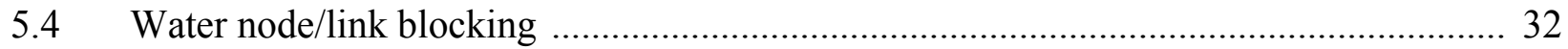

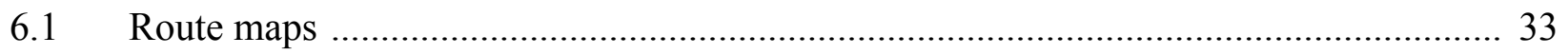


Page intentionally left blank 


\section{ACRONYMS AND ABBREVIATIONS}

\begin{tabular}{ll}
$*$ BRG & Barge, inland waterway \\
*M-M & Merchant Marine, deep draft waterway \\
$<$ TR> & Terminal Railroad \\
AAR & Association of American Railroads \\
AMTK & Amtrak (National Railroad Passenger Corporation) \\
CFR & Code of Federal Regulations \\
CN & Canada \\
CSXT & CSX Transportation \\
DOE & Department of Energy \\
DOT & Department of Transportation \\
EM & Office of Environmental Restoration and Waste Management \\
ESRI & Environmental Systems Research Institute, Inc. \\
FIPS & Federal Information Processing Standards \\
FRA & Federal Railroad Administration \\
GIS & Geographic Information System \\
GUI & Graphical user interface \\
HM-164 & Hazardous Materials Docket Number 164 \\
HRCQ & Highway Route Controlled Quantity \\
IAIS & Iowa Interstate \\
IC & Illinois Central \\
ID & Identification \\
LAT/LON & Latitude/longitude \\
L/D & Lock and Dam \\
NS & Norfolk Southern \\
ORNL & Oak Ridge National Laboratory \\
PC & Personal computer \\
PPU & Peoria and Pekin Union \\
SMIP & Safety Metrics Indicator Program \\
TIGER & Topologically Integrated Geographic Encoding and Referencing system \\
TRAGIS & Transportation Routing Analysis Geographic Information System \\
UP & Union Pacific \\
USGS & United States Geological Survey \\
WebTRAGIS & Transportation Routing Analysis Geographic Information System \\
WIPP & Waste Isolation Pilot Plant \\
WWW & World wide web \\
& \\
\hline &
\end{tabular}


Page intentionally left blank 


\section{TRANSPORTATION ROUTING ANALYSIS \\ GEOGRAPHIC INFORMATION SYSTEM \\ (TRAGIS) \\ USER'S MANUAL}

\section{INTRODUCTION}

In the early 1980s, Oak Ridge National Laboratory (ORNL) developed two transportation routing models: HIGHWAY, which predicts truck transportation routes, and INTERLINE, which predicts rail transportation routes. Both of these models have been used by the U.S. Department of Energy (DOE) community for a variety of routing needs over the years. One of the primary uses of the models has been to determine population-density information, which is used as input for risk assessment with the RADTRAN model, which is available on the TRANSNET computer system. During the recent years, advances in the development of geographic information systems (GISs) have resulted in increased demands from the user community for a GIS version of the ORNL routing models. In April 1994, the DOE Transportation Management Division (EM-261) held a Baseline Requirements Assessment Session with transportation routing experts and users of the HIGHWAY and INTERLINE models. As a result of the session, the development of a new GIS routing model, Transportation Routing Analysis GIS (TRAGIS), was initiated.

TRAGIS is a user-friendly, GIS-based transportation and analysis computer model. The older HIGHWAY and INTERLINE models are useful to calculate routes, but they cannot display a graphic of the calculated route. Consequently, many users have experienced difficulty determining the proper node for facilities and have been confused by or have misinterpreted the text-based listing from the older routing models. Some of the primary reasons for the development of TRAGIS are (a) to improve the ease of selecting locations for routing, (b) to graphically display the calculated route, and (c) to provide for additional geographic analysis of the route.

TRAGIS was originally written with the ArcView ${ }^{\mathrm{TM}}$ software, which is marketed by Environmental Systems Research Institute, Inc. (ESRI). ArcView is a versatile multifunctional GIS package. TRAGIS was written primarily in ArcView Avenue language, but several functions in TRAGIS (including the routing routines) were written in the $\mathrm{C}++$ programming language. TRAGIS operates on a UNIX ${ }^{\circledR}$ platform, primarily because of the size of the routing databases in the model. Additionally, several platform incompatibilities exist between the UNIX and Windows ${ }^{\mathrm{TM}}$ versions of ArcView. These incompatibilities make it difficult to run TRAGIS under the Windows platform. Also, each user must have a licensed copy of the ArcView ${ }^{\text {TM }}$ software. This requirement would get very expensive as the number of users increases.

Accessibility to DOE users has been a problem because TRAGIS was written for a SUN ${ }^{\mathrm{TM}}$ UNIX workstation. At that time the UNIX workstation was fast enough for the mapping features, but Windows personal computers (PCs) were not. Now that the speed and capability of Windows personal computers have increased dramatically, they are fully capable of performing the 
mapping function satisfactorily. The need to make TRAGIS more available to the DOE community indicated that development of the next version of TRAGIS as a world wide web (WWW) application might be the best option. Since the main routing software was written in $\mathrm{C}++$, it could be compiled for either a PC or a UNIX machine. Also, the user interface of TRAGIS was separate from the routing engine, it would be easier to build a new user interface and use essentially the same routing engine. During the development of WebTRAGIS (webbased TRAGIS), however, it was discovered that extensive modification of the routing engine in $\mathrm{C}++$ was required to give it a simple universal interface. This modification was completed, and now the routing engine can easily be used in other programs, such as Batch-TRAGIS for pass through analysis and for generating Safety Metrics Indicator Program (SMIP) normalization data, and the engine is expected to be used for TRANSCOST.

WebTRAGIS was developed to be accessible over the WWW using the capabilities of the Internet Explorer 5.0 ${ }^{\mathrm{TM}}$ web browser. WebTRAGIS consists of an access-controlled web page with a custom-built ActiveX $\mathrm{X}^{\mathrm{TM}}$ control, which serves as the user interface to the routing engine, which resides on the server and is sent the route description-information. The routing engine uses the information to calculate the route and then generates output listings as text files. The user interface can then pick up and display the output files. Since the mapping feature is still slow, especially when map data are sent over the internet, two different user interfaces were built - one with the mapping feature and one without the mapping feature. The user interface without the mapping feature is obviously much faster and will operate quickly and efficiently over the WWW. It is basically a direct replacement for HIGHWAY and INTERLINE with an easy-to-use Windows interface. The user's interface with the mapping feature is slower, and in order to keep the speed to an acceptable level, the large data files must reside on the user's PC. Therefore, it was decided to deploy the mapping version as a client-server application, where the map data files and user interface software reside on the user's PC and the routing engine and its large data files reside on the server. The client communicates over the internet with the server. The software was written to minimize the data transmission, so the speed of operation is virtually the same whether one is connected via a modem or a high-speed internet connection.

WebTRAGIS is designed to use the rail, highway, and waterway transportation modes for routing. The rail network used in the initial version of the model is the same database as that used in the INTERLINE model. This database, which was developed for the Federal Rail Administration (FRA) in the mid-1970s, is not a fixed-scale database and has been extensively modified since its inception by ORNL. Currently, a 1:100,000-scale database is being developed, and when this network is completed, it will be incorporated into WebTRAGIS. The road database is a 1:100,000-scale database, which was developed from the U.S. Geological Survey (USGS) Digital Line Graphs and the U.S. Bureau of Census Topologically Integrated Geographic Encoding and Referencing (TIGER) system. This waterway network information, for the inland waterway systems, is based on the USGS 1:2,000,000-U.S. Geodata. Deep-water routes are depicted in WebTRAGIS as straight-line segments. It is planned to incorporate a 1:100,000scale waterway database for the model so that all modes are at a consistent scale.

One of the features of WebTRAGIS is a consistent user interface between and among the transportation modes. Functions are similar for running rail, highway, or waterway routes. Some 
variations occur, such as prompts requesting the name of the railroad company to be used. However, when a user learns one portion of the WebTRAGIS system, it is not difficult for that person to run other portions of the model.

WebTRAGIS allows the selection of the origin and destination of a route from a list of node names. When selecting nodes, the program displays a list of state abbreviations from which the user selects a state. Next, a list of node names within that state is displayed. The user can scroll through this list and select a node. After a node is selected, WebTRAGIS displays the selected node's identification (ID) number. In addition to nodes at city locations and within the network, the WebTRAGIS databases contain hundreds of specific nodes for locations of commercial nuclear reactors, DOE sites, military installations, and other important nuclear-related sites.

After an origin and a destination are selected, the model is ready to calculate a route based on criteria established by option selections. A default set of criteria is active for each transportation mode in the model. After completing the route calculation, WebTRAGIS displays the standard route listing. The user can also view a detailed listing of the route and population-density information, which can be used with the RADTRAN risk model.

Option settings provide a mechanism to change various parameters used by the model for route calculations. Examples of some of the options include adjusting the penalty factors for the mainline classifications for rail routing, using preferred highway routes for radioactive materials, and running alternative routes for the different transportation modes in WebTRAGIS.

WebTRAGIS also provides functions to temporarily modify the routing networks. The user can select individual nodes and links or an entire state in which all nodes and links are blocked from the network.

This user's manual has six sections following this introductory section. Section 2 is a general overview of the WebTRAGIS. This section is very useful if the user has not worked with graphical user interface (GUI) programs. Rail, highway, and waterway features are discussed in Sects. 3-5, respectively. Section 6 describes the operation of the mapping functions. 
Page intentionally left blank 


\section{GENERAL OVERVIEW OF WebTRAGIS}

WebTRAGIS is written to operate as a Windows application for Microsoft Windows 32-bit operating systems. A 32-bit Windows PC with a copy of Internet Explorer (Version 5.0 or later) is necessary in order to use the WebTRAGIS software. The software is distributed as an ActiveX control or a downloadable client-server application. Instructions for installing the software are provided on the WWW page.

To start WebTRAGIS with mapping, click on START - Programs - TRAGIS - Tragis. Accessing the WWW page and logging on to the system will start WebTRAGIS without mapping. It will take a few seconds for WebTRAGIS to connect across the internet to the databases needed for the model. After the loading, the model will display a username window, which is used to control user access to the WebTRAGIS routing engine (Fig. 2.1).

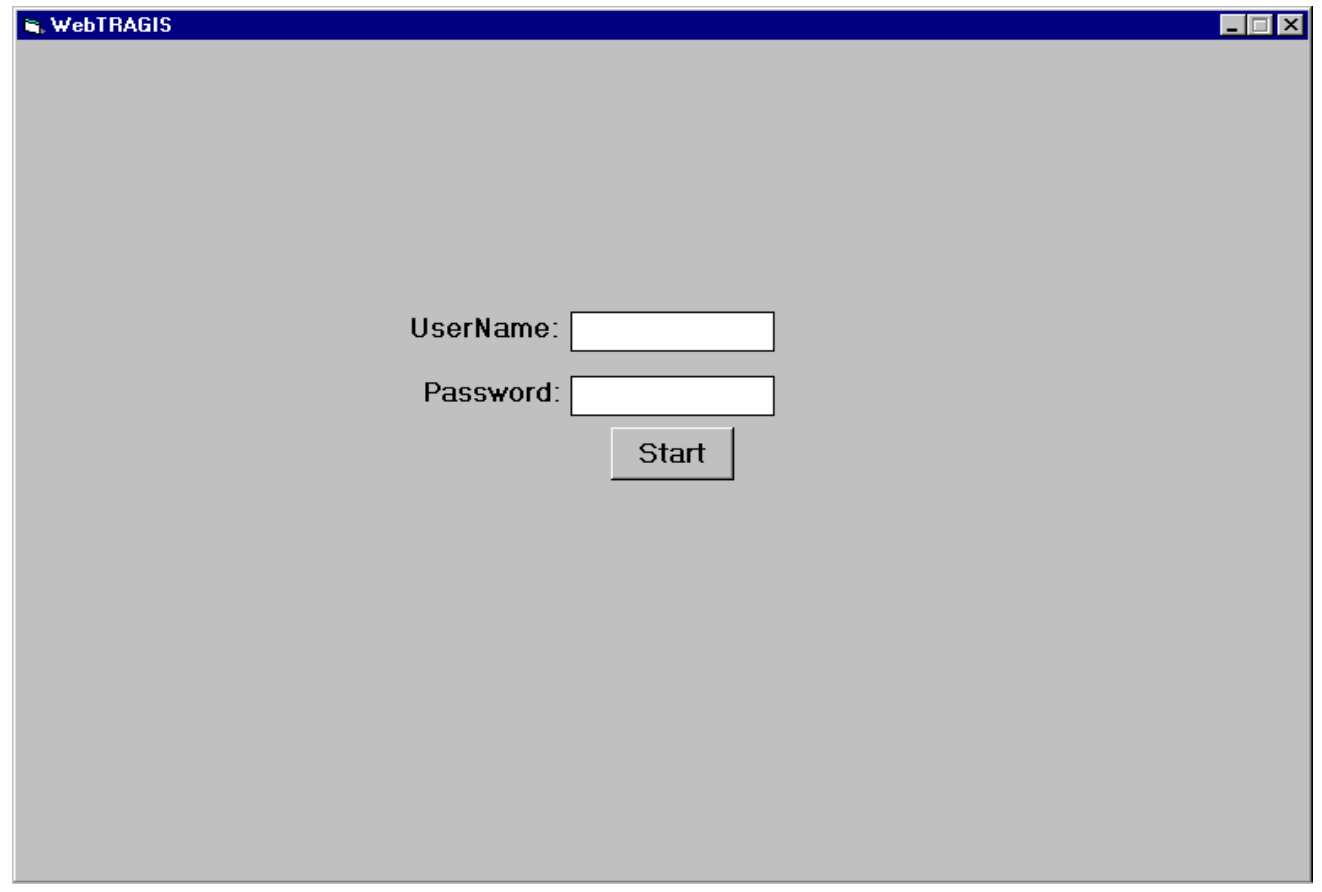

Fig. 2.1. Logon screen.

\subsection{WebTRAGIS LAYOUT}

WebTRAGIS has several tabs of options. It opens to the 'Select Origin and Destination' tab. Figure 2.2 shows how WebTRAGIS appears when the program has finished loading and the user has entered their username and password. There are five tabs on the WebTRAGIS WWW home page. There are six tabs on the WebTRAGIS with maps program - the same 5 that are on the WWW page plus a tab for maps. 


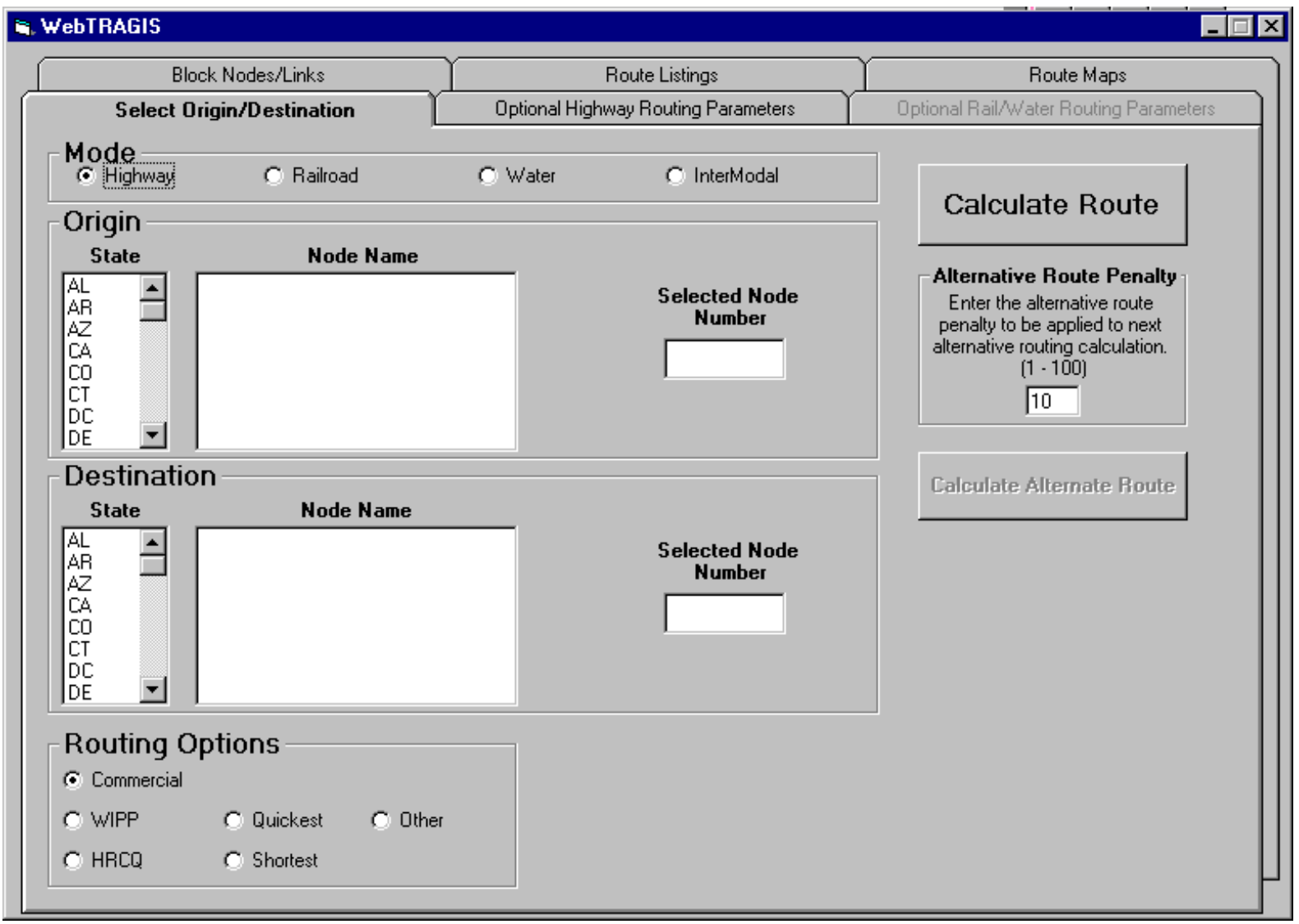

Fig. 2.2. WebTRAGIS.

\subsubsection{Tab 1-Select Origin/Destination}

This tab contain several options for selection mode; origin and destination, and route options; input of alternative route penalty; and, depending on the routing option selected, input of preferred route-weighting factor; and input of time and mile bias.

\subsubsection{Tab 2-Optional Highway Routing Parameters}

This tab contains six optional routing parameters. They are selection of one or two drivers, highway inspection, date and time options, toll-bias factor, other constraints, and road-lane-type penalty.

\subsubsection{Tab 3-Optional Rail/Water Routing Parameters}

This tab contains three optional routing parameters for railroads and two for water routing. The three railroad options are (1) Change Originating Railroad Preference, (2) Change Rail Line Type Weighting Factors, and (3) Modify Rail Transfer Penalties. The two water options are (1) Select Water Route Type and (2) Modify Mode Transfer Penalty. 


\subsubsection{Tab 4-Block Nodes/Links}

This tab contains four ways for blocking available routing features: block nodes, block links, block states, and block railroad companies.

\subsubsection{Tab 5-Route Listings}

This tab allows the user to view and print the input file and the four route output files. These are the detailed input file and the standard route listing, detailed route listing, population density, and the route latitude/longitude $(\mathrm{LAT} / \mathrm{LON})$ listing. After completing the route calculation, the standard listing is automatically displayed.

\subsubsection{Tab 6-Route Maps}

This tab is available only on the WebTRAGIS with the Maps version. On this tab are several buttons; these buttons are described in detail in Sect. 6 of this manual.

\subsection{RUNNING WebTRAGIS}

The remainder of this manual will be based on the individual transportation mode chosen within WebTRAGIS. Rail routing will be discussed first and next by highway and water routing. The long-range plans for WebTRAGIS include full intermodal capabilities so that users can route via two or three modes. In the initial version of WebTRAGIS, intermodal capabilities, as envisioned, do not exist as yet because of funding constraints. As an interim measure, an additional mode is available in WebTRAGIS. The rail-water mode is available for rail-waterway intermodal routing. This feature is not discussed in this manual; the functions of this combination mode are described in both the rail (Sect. 3) and waterway (Sect. 5) portions of this manual. 
Page intentionally left blank 


\section{RAIL ROUTING}

The WebTRAGIS model calculates rail routes that simulate the routing practices of the railroad companies in the United States. The basic concept of determining rail routes is to calculate the shortest path based on travel distance and traffic density on rail segments. Each segment of the rail-network database has a distance, in miles, and a variable signifying the volume of traffic density. The traffic-density information is divided into four classes as follows:

A-mainline - more than 20-million gross ton miles per year, B-mainline- between 5- and 20-million gross ton miles per year, A-branchline- between 1- and 5-million gross ton miles per year, and B-branchline-less than 1-million gross ton miles per year.

In addition to biasing the distance based on traffic density, the model also penalizes changing from one rail carrier to another. Finally, the model also reduces the impedance values on the originating rail carrier. These features replicate the practice of actual rail routing - which is that the originating carrier will attempt to keep the shipment on its system for as much of the total route as possible.

To set WebTRAGIS to calculate rail routes, the user needs to move the pointer over the Mode on the Select Origin/Destination tab and click the Rail option. This selects the mode Rail as the currently active mode in WebTRAGIS. After the rail mode is selected, the entire rail node listing is loaded, and the appropriate optional parameters are made visible. Figure 3.1 shows the display of WebTRAGIS after the rail network is activated.

\subsection{SELECT ORIGIN/DESTINATION TAB}

\subsubsection{Selecting Origin}

After the rail network is initialized, select the origin and destination for calculating a route. The first step is to select an origin for a route by first selecting the state, next selecting the node name, and then selecting the railroad company if more than one railroad services the selected node. The selected rail node number and railroad abbreviation are displayed. Repeat for selection of the destination. (The abbreviation CN represents Canada. Several rail lines in the current rail database extend into Canada.)

Figure 3.1 shows an example of node names for the state of Tennessee. In this example, the list has been scrolled about midway through the list of nodes (as is indicated by the position of the marker on the scroll bar), and the Knoxville node has been highlighted. After the desired node has been selected, a listing of all available railroads providing service at this location is identified. Then select one of the railroads by highlighting it. If there is only one servicing railroad company, it is automatically selected. WebTRAGIS now displays the selected node number and railroad company. 


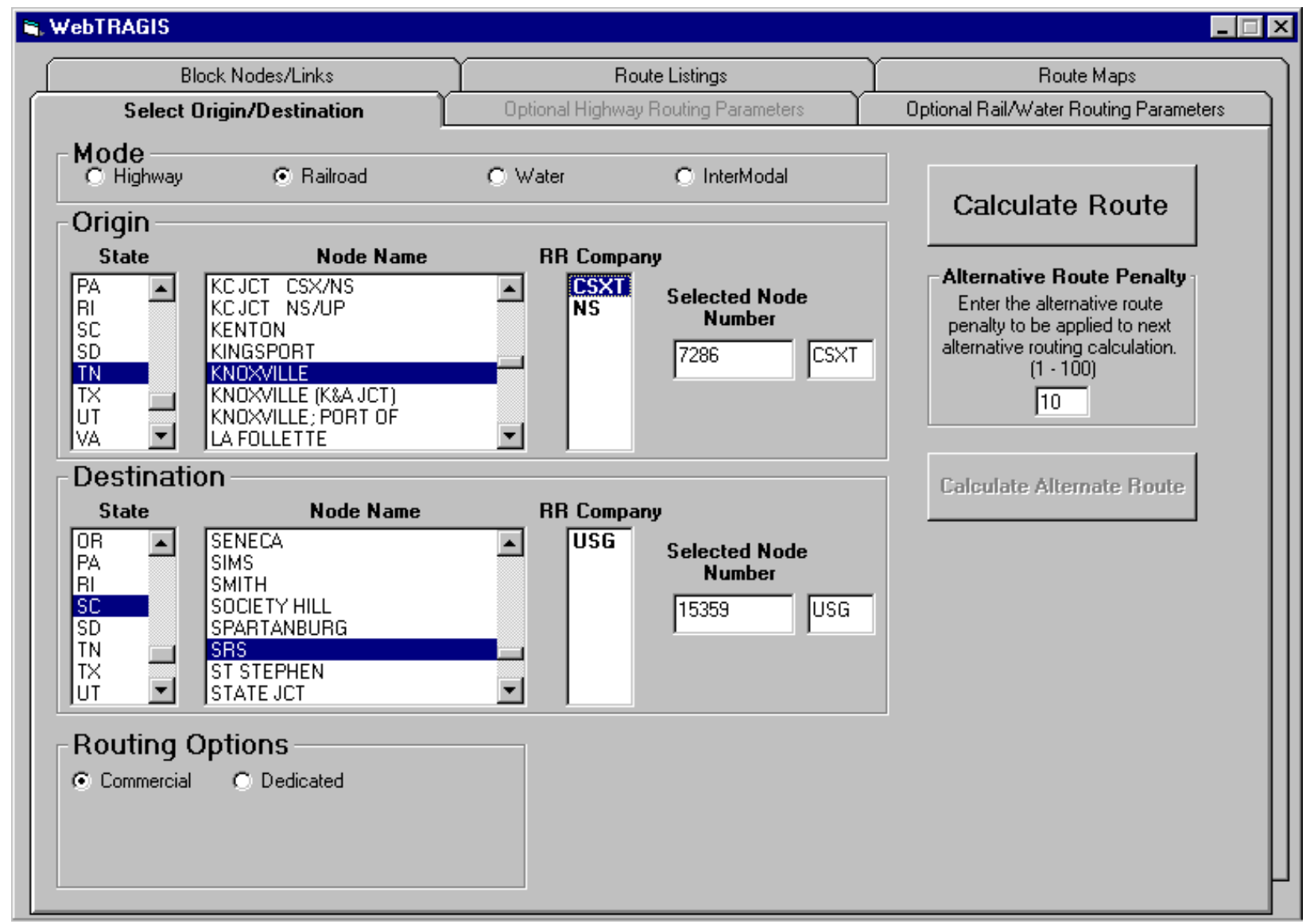

Fig. 3.1. Rail mode activated.

\subsubsection{Selecting Destination}

This same process is repeated for a destination location for a route. Selection of the route destination is the last required step before a route can be calculated. Press the Calculate Route button on the right side of the screen. The different origin or destination can be selected after a route has already been calculated. When this is done, the information from the previously calculated route is discarded, and all current information is used for the new route. The earlier destination or other selections will not be considered in the new route.

\subsubsection{Routing Options}

The routing type option is shown in Fig. 3.1. This option allows a choice between the default general commercial freight routing option or the dedicated-train routing option. With the dedicated-train routing option, the transfer penalty between railroad systems and the originating railroad advantage are eliminated. To switch between these two, click the appropriate choice. 


\subsection{Calculate Route and Calculate Alternative Route}

After a destination has been determined, click the Calculate Route button on the right side of the screen. If an origin or a destination is not selected, a message reminding you to select these will be displayed. WebTRAGIS will calculate the rail route and then display a window that shows the standard listing for the route.

After a route has been calculated, the Calculate Alternative Route button becomes active, allowing the user to generate alternative routes. To calculate an alternative route, go back to the Select Origin/Destination tab and then click the Calculate Alternative Route button. When an alternative route (or another route) is calculated, it overwrites all of the output files from the previous route. Therefore, you must save or print all route files before running an alternative (or another) route. An alternative route is generated by penalizing the links comprising the current route by the Alternative Route Penalty Factor in preparation for running the alternative route when the Calculate Alternative Route is clicked.

\subsection{ROUTE LISTINGS TAB}

The Route Listings tab provides access to input and output listings of routes and populationdensity information of the most recently calculated route. The displayed listing can be saved or printed. Figure 3.2 shows the route listings.

The standard listing identifies only the origin and destination, any transfer locations, and larger cities along the route. This listing also identifies the railroad used for each portion of the route, a cumulative mileage figure for each location listed, a breakdown of mileage by railroad and line classification, and a summary of mileage by state.

The detailed listing provides much more information on the route. Every node on the route is listed along with information on link characteristics. Not every node in the database has a name, so node numbers are listed. Link information includes the link number; the distance of the link; the line classification code; a traffic volume code; a speed limit for freight trains; and if the operating railroad is using trackage rights over this line, the abbreviation of the railroad owning the tracks. As with the standard listing, summary information by railroad and state follows the route listing.

The population-density information is viewed by clicking the Population Data button. A listing of the population density information for the route is displayed. The basic table includes 12 population-density categories ranging from 0 to over 9996 people per square mile. The entries in the table show the distance that the route travels in each category. At the end of the table, summary information is provided for the route. This information combines the data from the 12 categories into rural, suburban, and urban groups and also provides a weighted populationdensity value for each of these groups. This information is used as input for routing risk analysis using the RADTRAN or RISKIND computer codes. 


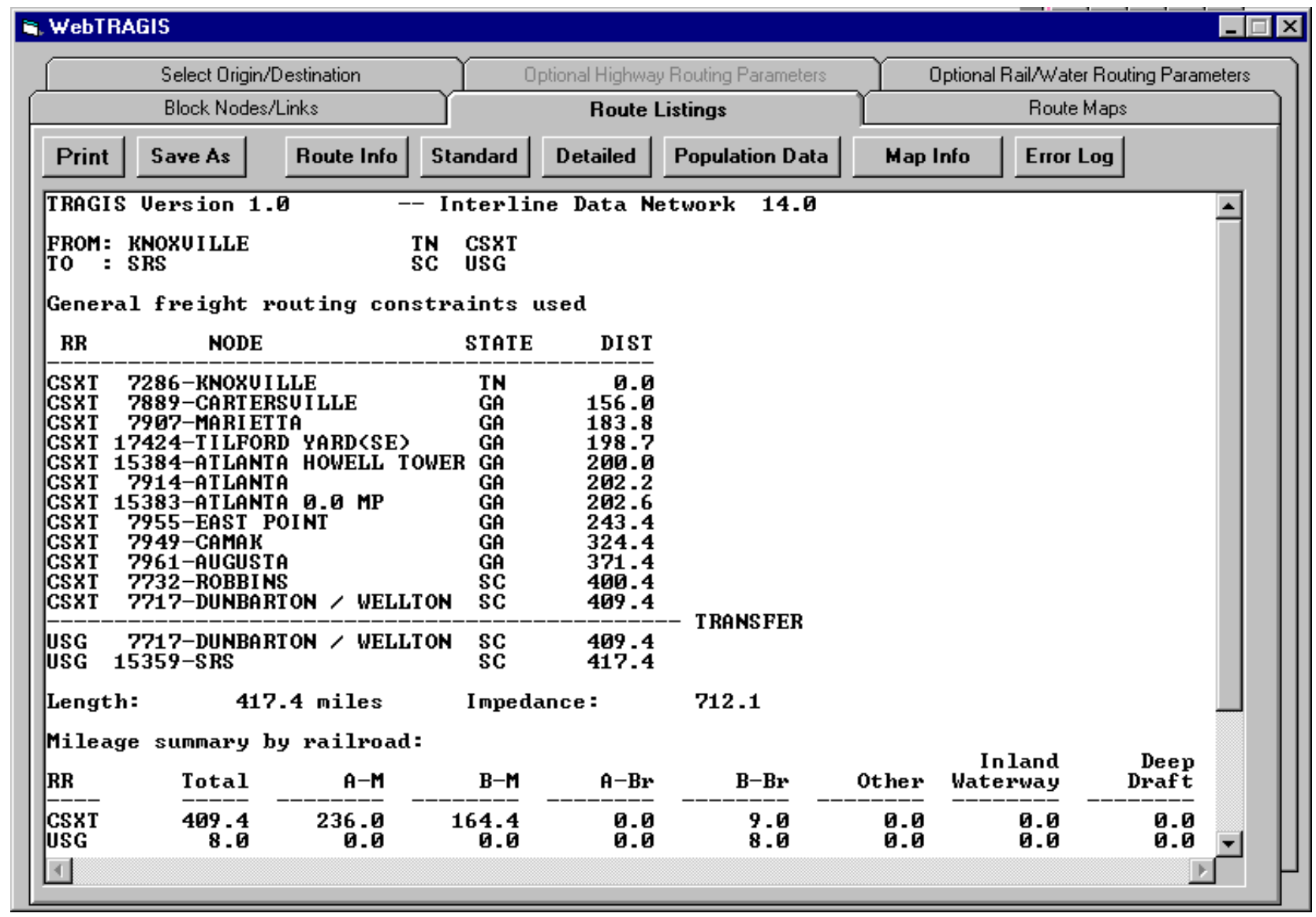

Fig. 3.2. Rail-route listings.

The final items on the Route Listings tab are the Print and Save As buttons. When the Print button is clicked, the listing currently being viewed is sent to the printer. (Note: Be sure to display the desired information to the screen before printing). When the Save As button is clicked, a file selection dialog box is displayed. The file name and location can then be selected, and the listing currently being displayed can be saved to that selected file.

\subsection{OPTIONAL RAIL/WATER ROUTING PARAMETERS TAB}

The Optional Rail/Water Routing Parameters tab provides access to a number of parameters that control the routing functions. When rail is the active mode, Optional Rail/Water Routing Parameters tab is available, and the Optional Highway Routing Parameters tab is not.

When the Optional Rail/Water Routing Parameters tab is selected, a window of the rail options is displayed. Figure 3.3 shows the rail options window. Within this window, available options can be selected. Click on the item of interest to select it. The following sections discuss the various rail options. 


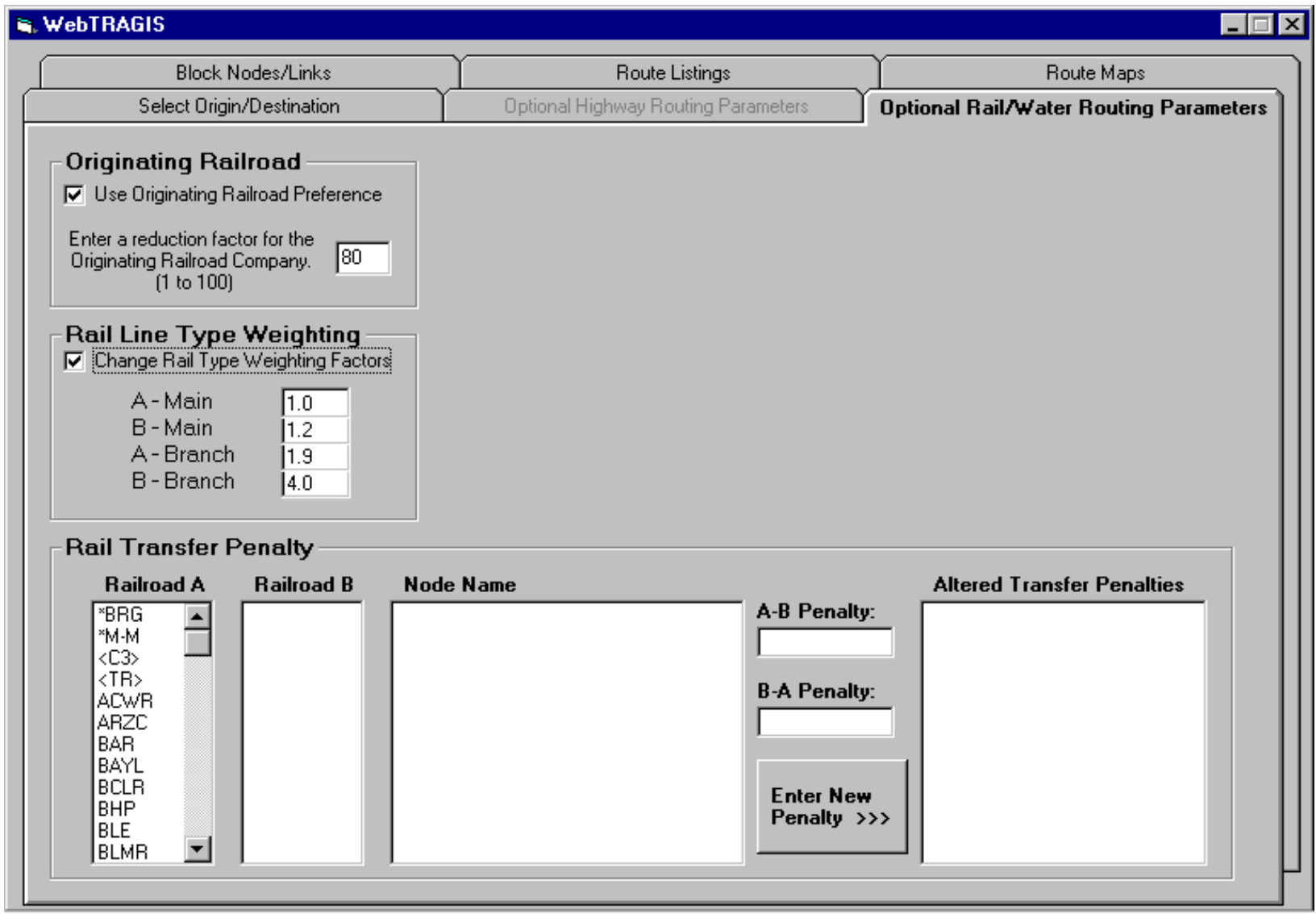

Fig. 3.3. Optional rail-routing parameters.

\subsubsection{Rail Line Type Weighting}

The weighting factor option allows adjustments to the factors that are used to calculate routes. This window is shown in Fig. 3.3. The default values are displayed for each penalty factor. Any of the variables can have a new value assigned by entering a new value in the appropriate box. The appropriate factors are multiplied by the distance of each link or railroad. Using the default values, an A-Mainline link has an impedance that is the same as its distance, whereas the impedance of a B-Branchline link is four times its distance.

\subsubsection{Originating Railroad Preference}

The impedance of the originating railroad is multiplied by a factor of $80 \%$. This percentage reduces the impedance of the originating railroad, thereby encouraging the shipment to remain with the originating railroad as long as practicable.

\subsection{BLOCK NODES/LINKS TAB}

The Block Nodes/Links tab allows the user to block portions of the rail database or different rail companies. These features can be useful when there is a need to analyze various scenarios (e.g., 
determining a route that avoids a damaged bridge or section of rail line and analyzing rail mergers). The Block Nodes/Links tab has three functional groupings. The first group involves blocking nodes. The second group involves blocking links. Finally, the last group allows for the blocking of individual railroad companies. The window is shown in Fig. 3.4 below.

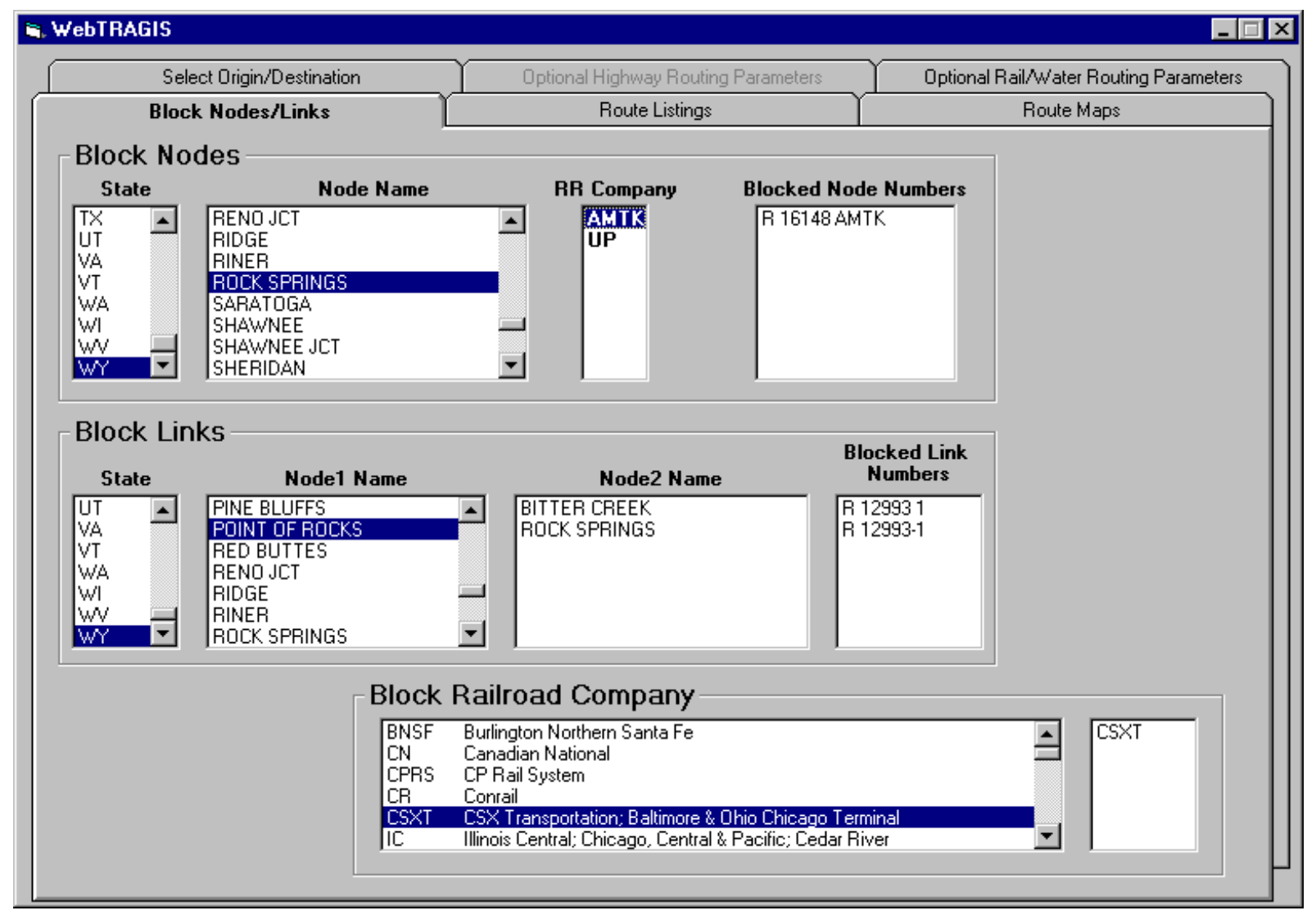

Fig. 3.4. Rail node/link blocking.

\subsubsection{Node Blocking}

To block a rail node, click the state of interest and find the node name to be blocked. As an example, Rock Springs, Wyoming, is served by the Union Pacific (UP) and by Amtrak (AMTK), the national rail passenger service. For other nodes, several rail companies could be listed. Thus, a node could be blocked for one railroad, but remain available for another. To remove an entry from the Blocked Nodes list, double-click on it.

\subsubsection{Link Blocking}

To block a link, click the state of interest and find the node of one end of the link to be blocked. Then select the other end node of the link. The blocked link is then displayed. (Note: There are two entries shown, one ending in ' 1 ' and the other ending in ' -1 '). These block the link in both directions. 


\subsubsection{Block Railroad Company}

The rail network in WebTRAGIS is subdivided into 94 subnetworks. The Block Railroad Company tab provides a method to remove a railroad subnetwork from consideration. Figure 3.4 shows the rail system window as it would be displayed. The window provides a list of the railroad names for the rail systems in the rail database. A number of rail systems are comprised of several separate railroads that are owned by a single company. An example, shown on Fig. 3.4, is the Illinois Central (IC), which also owns the Chicago, Central \& Pacific and the Cedar River. To remove a rail system from consideration, scroll through the list to locate the desired railroad and double-click on the name to block it. The abbreviation will appear in the box to the right. 
Page intentionally left blank. 


\section{HIGHWAY ROUTING}

The WebTRAGIS model can calculate a number of different types of highway routes. By default, the model calculates commercial highway routes; but with the change of an option, the model can determine routes that meet the U.S. Department of Transportation (DOT) regulations for shipments of highway route-controlled quantities (HRCQ) of radioactive material, specified routes for shipments to WIPP, the shortest, or the quickest route.

To set WebTRAGIS to calculate highway routes, the user needs to move the pointer over the Mode on the Select Origin/Destination tab and click the Highway option. This selects the mode Highway as the currently active mode in WebTRAGIS. After the Highway mode is selected, the entire highway node listing is loaded, and the appropriate optional parameters are activated. Figure 4.1 shows the display of WebTRAGIS after the highway network is activated.

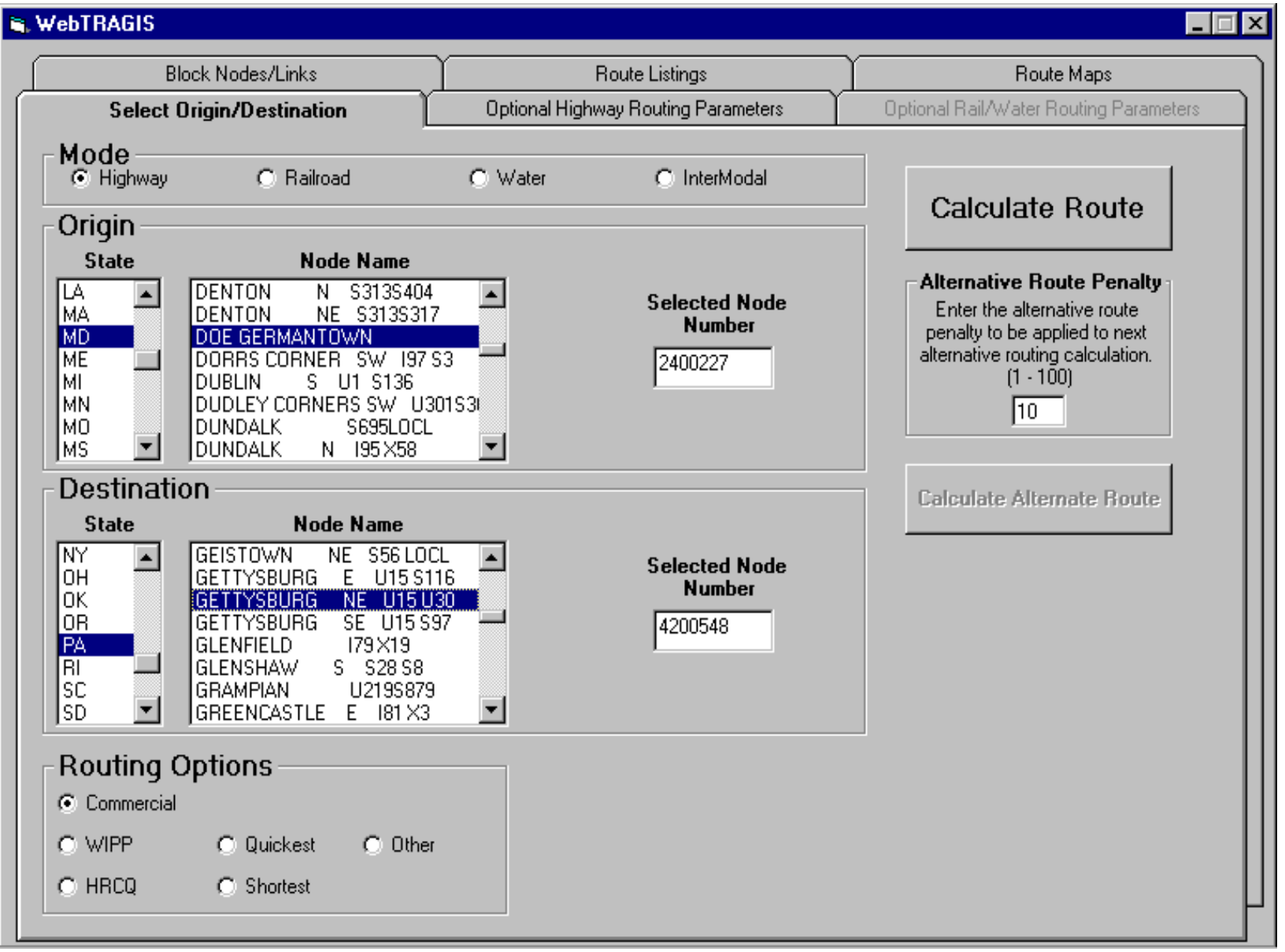

Fig. 4.1. Highway routing. 


\subsection{SELECT ORIGIN/DESTINATION TAB}

\subsubsection{Selecting Origin}

After the highway network is initialized, select the origin and destination for calculating a route. The first step is to select an origin for a route by first selecting the state, and then selecting the node name. The selected highway node number is displayed. Repeat for selection of the destination. Figure 4.1 shows an example of node names for the state of Maryland. In this example, the list has been scrolled partway through the list of nodes (as is indicated by the position of the marker on the scroll bar), and the DOE-Germantown node has been highlighted. WebTRAGIS now displays the selected node number.

\subsubsection{Selecting Destination}

This same process is repeated for a destination location for a route. Selection of the route destination is the last required step before a route can be calculated. For this example, Gettysburg, Pennsylvania has been selected. Press the Calculate Route button on the right side of the screen. A different origin or destination may be selected after a route has been calculated. When this is done, the information from the previously calculated route is discarded, and all current information is used for the new route. An earlier destination or other selections will not be considered in the new route.

\subsubsection{Routing Options}

The Routing Options are shown in Fig. 4.1. These options allow a choice between the Commercial (default), HRCQ, WIPP, Quickest, Shortest, and Other routing options. Click the appropriate choice.

\subsubsection{Calculate Route and Calculate Alternative Route}

After a destination has been determined, click the Calculate Route button on the right side of the screen. If an origin or destination is not selected, a message reminding you to select these will be displayed. WebTRAGIS will calculate the highway route, and then display a window which shows the standard listing for the route.

After a route has been calculated, the Calculate Alternative Route button becomes active allowing the user to generate alternative routes. To calculate an alternative route, go back to the Select Origin/Destination tab, and then click the Calculate Alternative Route button. When an alternative route (or another route) is calculated, it overwrites all of the output files from the previous route. Therefore, you must save or print all route files before running an alternative (or another) route. An alternative route is generated by penalizing the links comprising the current route by the Alternative Route Penalty Factor in preparation for running the alternative route when the Calculate Alternative Route is clicked. 


\subsection{ROUTE LISTINGS TAB}

The Route Listings tab provides access to the input and output listings of routes and populationdensity information of the most recently calculated route. The displayed listing can be saved or printed (Fig. 4.2).

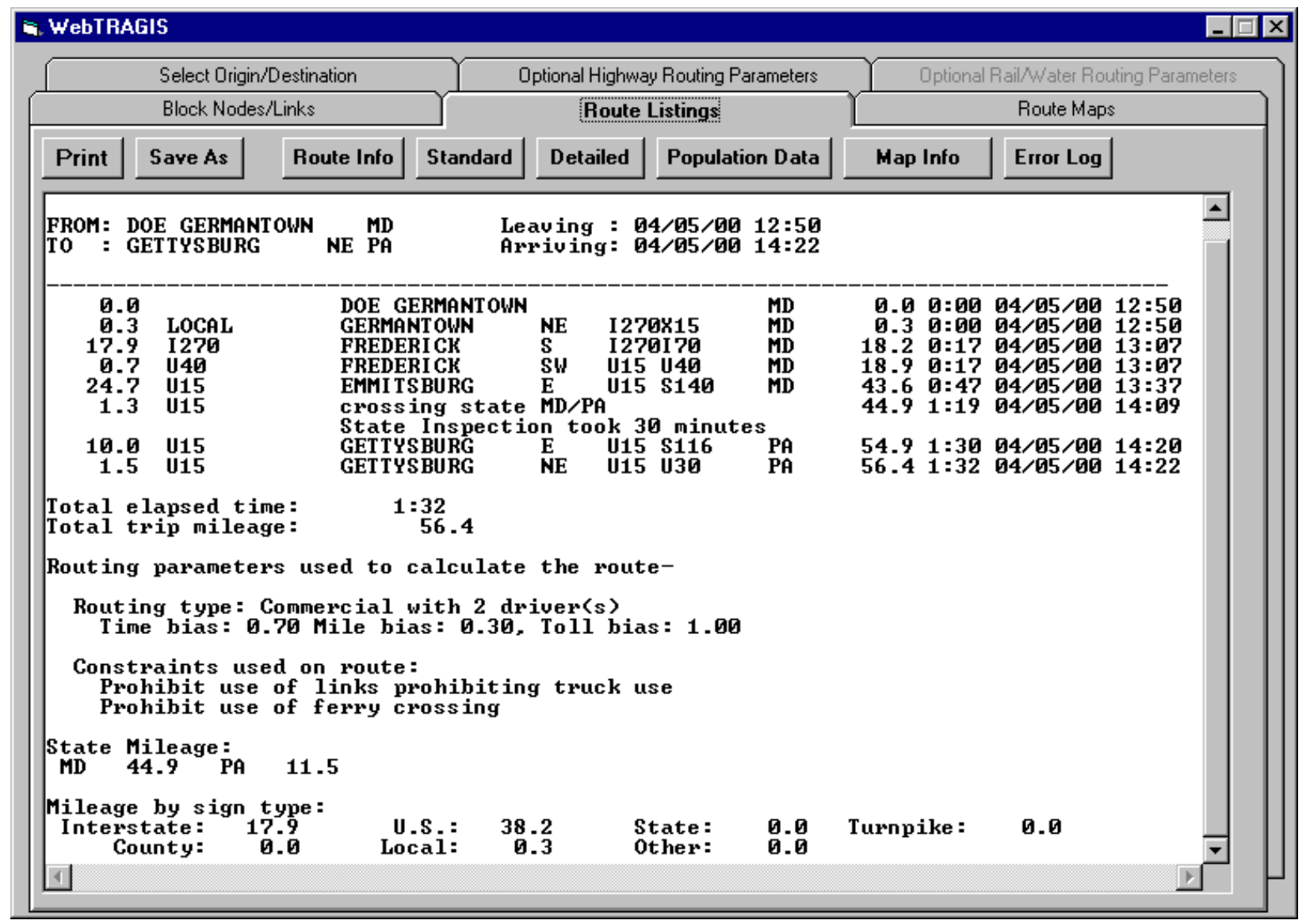

Fig. 4.2 Highway-route listings.

For highway routes, standard and detailed route listings are available. The standard listing is the shorter route listing, which is the one used most often (Fig. 4.2). This listing is for a route between DOE offices in Germantown, Maryland, and Gettysburg, Pennsylvania. The origin and destination, along with the departure and arrival date and time, are identified at the top of the listing. Next, a description of the route is provided. The first column is the distance, in miles, between each location in the listing. Following this is an identification of the road. Up to two road identifications are listed (e.g., a dual-designation road such as I-40/I-75). The first letter of the road number is a designation of the road type. Interstate highways start with an I, U.S. highways start with an $\mathrm{U}$, state highways start with an $\mathrm{S}$, turnpikes and tollways start with a $\mathrm{T}$, county roads start with a $\mathrm{C}$, and local roads start with an L. Other types of roads, such as 
farm-to-market roads in Texas, may start with other letters. The route number or an alphabetic abbreviation of the road follows the designation letter. Next the name of the node is listed. In some cases, actual facilities are identified, such as DOE-Germantown. Most often, nodes are identified by the nearest town or city, followed by the direction that this location is from the named location. Junction information is provided to assist in the node description. This information may include the two roads that form an intersection or the interstate route number and the exit number. The state is identified, and this identification is followed by a cumulative mileage and time columns. Finally, the date and time when the shipment is expected to pass the node are given. By default, the model assumes the departure time to be the current time from the computer. The user can set the departure time through the Optional Highway Routing Parameters tab, which is discussed in Sect. 4.3.

In the example shown in Fig. 4.2, the route originates at DOE-Germantown at 12:50 p.m. The route travels 0.3 miles on a local road and turns onto I-270 at Exit 15. This location is northeast of Germantown, Maryland. After traveling 17.9 miles on I-270, the shipment exits the Interstate at the junction of I-270 and I-70, south of Frederick, and then travels 0.7 miles on U.S. 40 to the junction of U.S. 15 and U.S. 40, southwest of Frederick, Maryland. At this location, the length of the route is 18.9 miles, and the trip has taken about 18 minutes. The route follows U.S. 15 for 24.7 miles to Emmitsburg, Maryland. This location is the last node encountered on the route in Maryland. (At least one line will appear in the route listing for every state that is on a route.) After another 12.8 miles on U.S. 15, the shipment arrives at the destination, which is Gettysburg, Pennsylvania. The location of this node is northeast of town at the junction of U.S. 15 and 30.

Following the route description, a summary of the total elapsed time and trip mileage is given. The routing parameters used to calculate the route is also provided along with a summary of mileage by state and a breakdown of mileage by highway sign type.

The detailed route listing is basically the same as the standard route listing other than that every node on the route is listed on the description. The length of a route listing for a cross-country route can be very long.

Population-density information can be obtained for the most recent calculated route by choosing the Population button in the Route Listings tab. A window is generated that lists the population-density information for the route. The basic table includes 12 population-density categories ranging from 0 to over 9996 people per square mile. The entries in the table show the distance that the route covers in each category. At the end of the table, summary information is provided for the route. This information combines the data from the 12 categories into rural, suburban, and urban groups and also provides a weighted population-density value for each of these groups. This information is useful as input for routing risk analysis using the RADTRAN computer code at Sandia National Laboratories or the RISKIND computer code at Argonne National Laboratory. 


\subsection{OPTIONAL HIGHWAY ROUTING PARAMETERS TAB}

The Optional Highway Routing Parameters tab provides access to a number of parameters that control the routing functions. Selecting the Optional Highway Routing Parameters tab, a window like that shown in Fig. 4.3 is displayed. This window identifies all the options that are available for road routing. To select an option, click on the appropriate option.

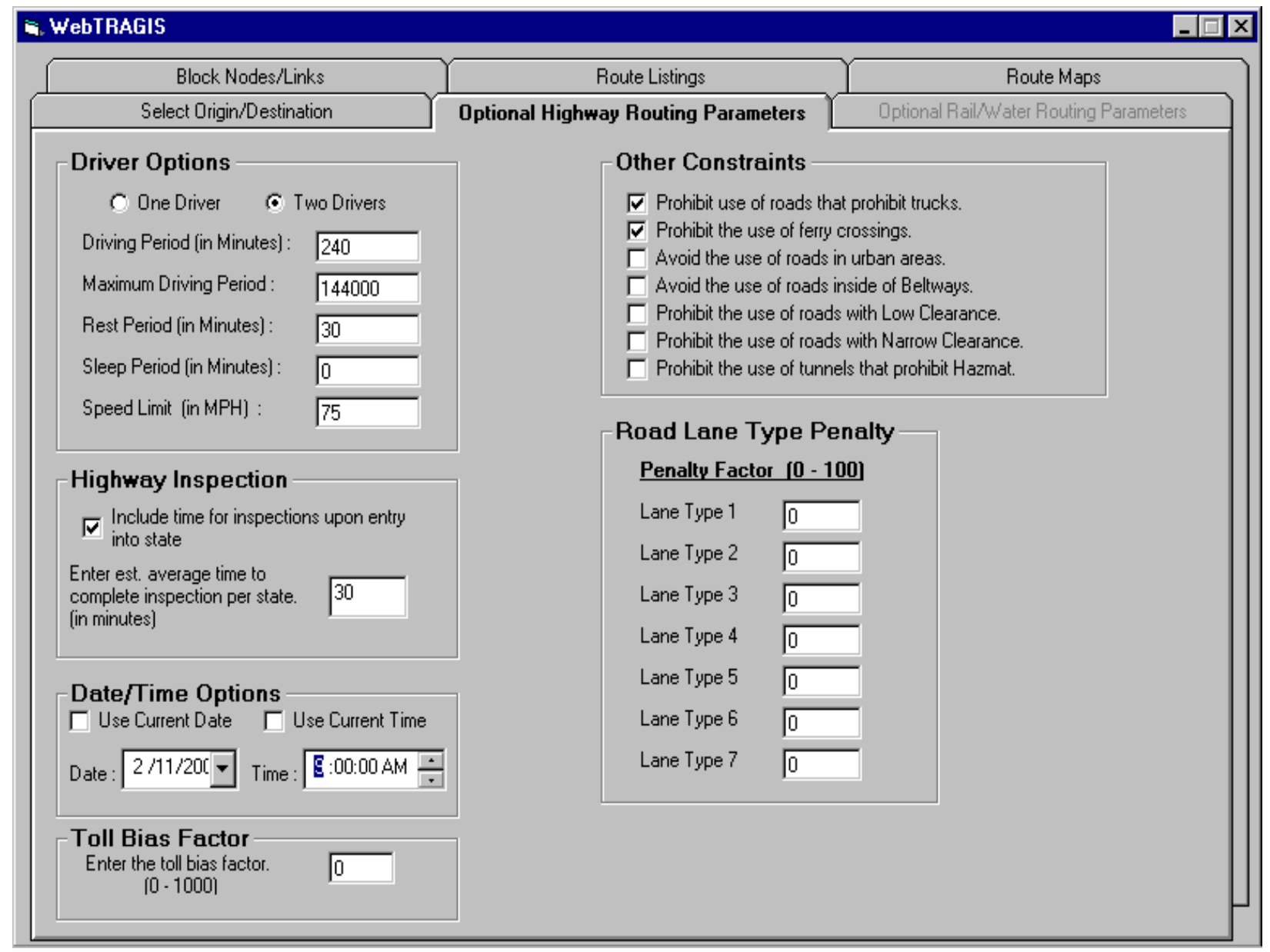

Fig. 4.3. Optional highway routing parameters.

\subsubsection{Driver Options}

When changing the Driver Options is desired, the user must select between the one or two drivers options. Figure 4.3 shows this option. The default is Two Drivers. Each of these options has several parameters that may be changed for a particular route. Double-click on either of the options to view the additional parameters. You may change these parameters by editing the displayed values. 


\subsubsection{One Driver}

The next four items in this option window involve the periods of time for driving and resting. With a One Driver shipment, the default follows a pattern that the driver works for 5 hours and then takes a 0.5 -hour break. After this break, another 5 hours of driving can occur, for a total of 10 hours, before an 8-hour rest period is required. You can change the amount of driving time before the short break and between major rest periods by entering new values in the driving time fields. The latter two lines request the length of the short and long break periods, respectively.

The final item of this option permits you to specify the maximum speed that a shipment will travel. Congressional action in 1995 lifted national speed limits and allowed states to specify their own limits. In certain cases, an upper limit may need to be specified for the speed of the shipment. The default value for this variable in WebTRAGIS is $75 \mathrm{mph}$. To specify a maximum travel speed of $55 \mathrm{mph}$, the model will use the speed specified in the truck database - except that those links with speeds higher will be assumed to be the value the user specified. Adjusting this value may affect the route calculation; it is also used to determine arrival times that are identified on the route listing.

\subsubsection{Two Drivers}

These items in this option window involve the periods of time for driving and resting. With two drivers, the default follows a pattern of 4 hours of driving followed by a 0.5 -hour break. This pattern is followed throughout the duration of the shipment because one driver can rest while the other is driving.

The final item of this option allows the maximum speed of a shipment to be specified. Congressional action in 1995 lifted national speed limits and allowed states to specify their own limits. In certain cases, an upper limit may need to be specified for the speed for the shipment. The default value for this variable in WebTRAGIS is $75 \mathrm{mph}$. To specify a maximum speed of $55 \mathrm{mph}$, the model will use the speed specified in the truck database-except that those links with higher speeds will be assumed to be the value the user specified. Adjusting this value will not affect the route calculation; it is also used to determine arrival times that are identified on the route listing.

\subsubsection{State Inspection}

WebTRAGIS has an option to perform state inspections of a shipment when that shipment is transported into a new state. Figure 4.3 is the option that is displayed when the Highway Inspection option is checked. If the user clicks the checkbox below Highway Inspection, the inspection time box is displayed. The default value is 30 -minutes; this value can be changed by entering a new value.

This option will create a delay every time the calculated route crosses a state boundary to simulate the delay a shipment may experience if a state inspection is required. Use of this option 
will not change a route (e.g., such as minimizing the number of states traversed). It will increase only the travel time for the shipment.

\subsubsection{Date/Time Options}

This option allows the user to specify the departure date and time for the shipment. By default, WebTRAGIS uses the current date and time from the computer. If the departure date needs to be specified, select the date with the drop-down calendar, as shown in Fig. 4.3. The departure time can be entered using the drop-down selector. If the route origin is not located in the same time zone as the computer running WebTRAGIS, the input time will be adjusted by the model (e.g., if the origin is in the central time zone, the departure time is specified as 16:30, and the computer is in the eastern time zone, WebTRAGIS will adjust the departure time to 3:30 p.m.).

\subsubsection{Other Routing Constraints}

Figure 4.3 shows the Other Constraints option. Checking the box before the item can activate any of these constraints. Two of the constraints are automatically activated by WebTRAGIS: the commercial truck and ferry crossing constraints.

The commercial truck constraint prohibits the program from using any route that restricts commercial truck traffic. An example of this is the Baltimore-Washington Parkway; no commercial truck traffic is allowed on this road. Thus, for any routing of commercial traffic, this constraint needs to be active.

Several ferry crossings are in the WebTRAGIS road database, such as those between Long Island, New York, and Connecticut. The ferry-crossing constraint prohibits the use of a ferry on a route. To use the ferries that are in the database, the user would uncheck the box (Prohibit the use of ferry crossings).

Roads that pass through urbanized areas with populations exceeding 100,000 are identified in the road database. By checking this option, Avoid the use of roads in urban areas, the model will not use any roads within any urbanized areas.

Another available constraint restricts the use of all roads within interstate beltways of larger metropolitan areas. This constraint is not related to the HRCQ-preferred routing (HM-164) option. Use of this constraint will cause the route to avoid going within the major beltways in large cities. To activate this constraint, check the box, Avoid the use of roads inside of Beltways.

The next two constraints involve low clearance and narrow road clearance. Road segments with height clearances of less than $13 \mathrm{ft} 6$ in and width restrictions of $8 \mathrm{ft}$ or less are identified and will prohibit the use of these road segments. Each of these constraints can be activated when checking the box for the appropriate restriction. 
The final constraint is identified as a tunnel. All tunnels that have hazardous materials restrictions are identified in the road database, and when this item is activated, the program will prohibit calculating routes that include these restricted tunnels.

\subsection{BLOCK NODES/LINKS TAB}

The Block Nodes/Links tab allows the blocking of a portion of the road database. This feature can be useful for analysis of various scenarios such as road closures, construction zones, or damaged bridges. You can block portions of the road database by selecting nodes, links, or entire states. Figure 4.4 shows the Block Nodes/Links window.

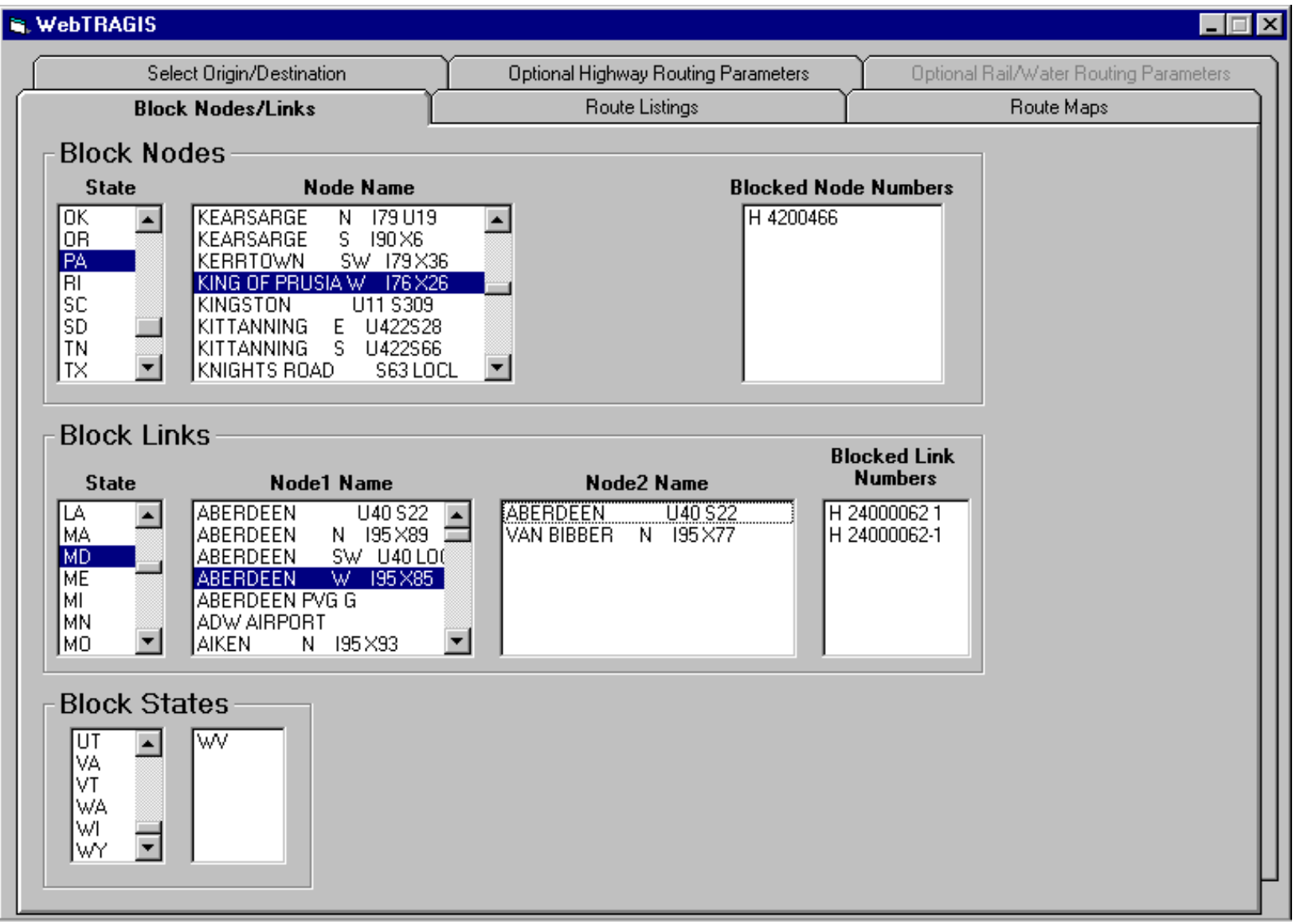

Fig. 4.4. Highway node/link blocking.

\subsubsection{Node Blocking}

Nodes can be blocked in the road database by making all the links that emanate from the node ineligible for routing. To block a node, select the state in which the node exists. The Node Name list will be populated with node names for that state. Now select the node to be blocked by scrolling to the name and clicking on it. The node number will then appear in the Blocked Node Numbers list. 
The node numbers are six or seven digits. The right-most five digits are unique to the node within a state, and the digits to the left of the five digits are the state Federal Information Processing Standard (FIPS) code for the state. For example, code 47 is Tennessee. A node number may be removed from the Blocked Node Numbers list by double-clicking on it.

\subsubsection{Link Blocking}

Since a link is defined by its nodes, you will be choosing the link by selecting its endpoints. Block links in the road database by first choosing the State. After a state is chosen, the Node1 Name list will be populated. The Node2 Name list will be populated with all of the nodes connected to Node1. Select Node2 from the list in Node2 Name list. The Blocked Link Numbers list will now contain two entries, the first ending with a ' 1 ' and the second ending with $a^{\prime}-1$ '. These block the link in both directions. If you want to block a link in only one direction, double click on the undesired entry, and it will be removed from the list.

\subsubsection{State Blocking}

An entire state can be temporarily removed from the road routing database by selecting the state (or states) from the Blocked States list. The blocked states will appear in the list to the right. A state may be removed from this list by double-clicking on the state abbreviation. Figure 4.4 shows that an alphabetical list of state abbreviations is displayed in a list. Scroll through the list and click the state to be removed. 
Page intentionally left blank. 


\section{WATERWAY ROUTING}

Waterway routing is available to users of WebTRAGIS. The waterway database consists of both inland waterways and deep-water routes. Inland waterways include all channels with a minimum depth of 9 feet. The deep-water network consists of connections between ports on the Pacific Ocean, Gulf of Mexico, Atlantic Ocean, and Great Lakes regions. Transfers between the inland and deep-water routes are treated as break-of-bulk points.

To set WebTRAGIS to calculate water routes, the user needs to move the pointer over the Mode on the Select Origin/Destination tab and click the Water option. This selects the mode Water as the currently active mode in WebTRAGIS. After the Water mode is selected, the entire water node listing is loaded, and the appropriate optional parameters are made active. Figure 5.1 shows the display of WebTRAGIS after the water network is activated.

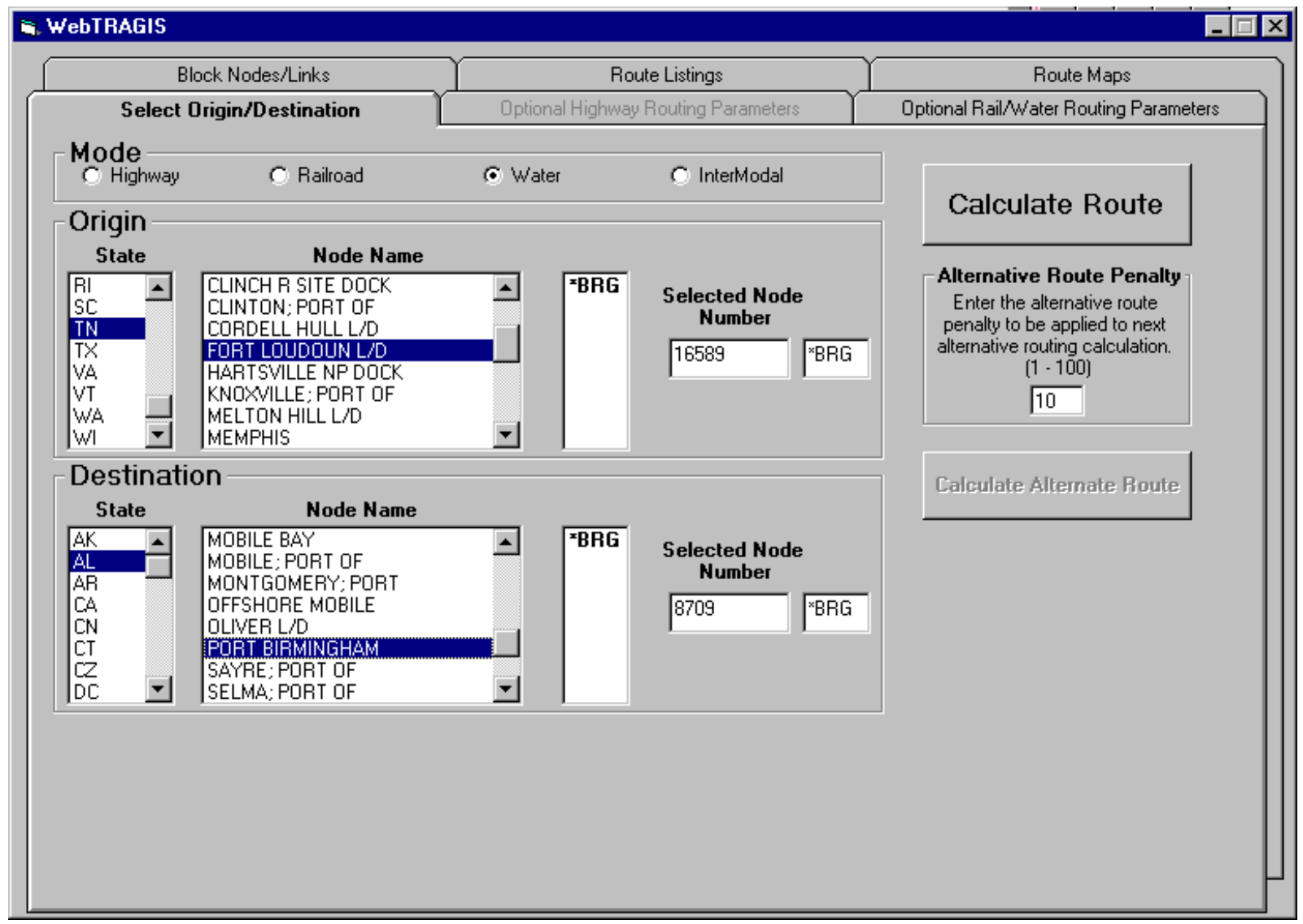

Fig. 5.1. Water routing. 


\subsection{SELECT ORIGIN/DESTINATION TAB}

\subsubsection{Selecting Origin}

After the water network is initialized, select the Origin and Destination for calculating a route. The first step is to select an origin for a route by first selecting the state, then selecting the node name, and then selecting the subnetwork if more than one services the selected node. The Selected Node Number and subnetwork abbreviation are displayed.

Figure 5.1 shows an example of node names for the state of Tennessee. In this example, the list has been scrolled about midway through the list of nodes (as is indicated by the position of the marker on the scroll bar), and the Knoxville node has been highlighted. After the desired node has been selected, a listing of all available subnetworks providing service at this location is identified. Then select one of the railroads by highlighting it. If there is only one servicing subnetwork, it is automatically selected. WebTRAGIS now displays the selected node and subnetwork.

\subsubsection{Selecting Destination}

This same process is repeated for a destination location for a route. Selection of the route destination is the last required step before a route can be calculated. Press the Calculate Route button on the right side of the screen. A different Origin or Destination can be selected after a route has already been calculated. When this is done, the information from the previously calculated route is discarded, and all current information is used for the new route. The earlier destination or other selections will not be considered in the new route.

\subsubsection{Calculate Route and Calculate Alternative Route}

After a destination has been determined, click the Calculate Route button on the right side of the screen. If an origin or destination is not selected, a message reminding you to select these will be displayed. WebTRAGIS will calculate the water route and then display a window that shows the standard listing for the route.

After a route has been calculated, the Calculate Alternative Route button becomes active, allowing the user to generate alternative routes. To calculate an alternative route, go back to the Select Origin/Destination tab, and then click the Calculate Alternative Route button. When an alternative route (or another route) is calculated, it overwrites all of the output files from the previous route. Therefore, you must save or print all route files before running an alternative (or another) route. 


\subsection{ROUTE LISTINGS TAB}

The Route Listings tab provides access to input and output listings of routes and populationdensity information of the most recently calculated route. The displayed listing can be saved or printed. Figure 5.2 shows the route listings.

The standard listing identifies only the origin and destination, any transfer locations, and larger cities along the route. This listing also identifies the subnetwork used for each portion of the route, a cumulative mileage figure for each location listed, a breakdown of mileage by subnetwork and line classification, and a summary of mileage by state.

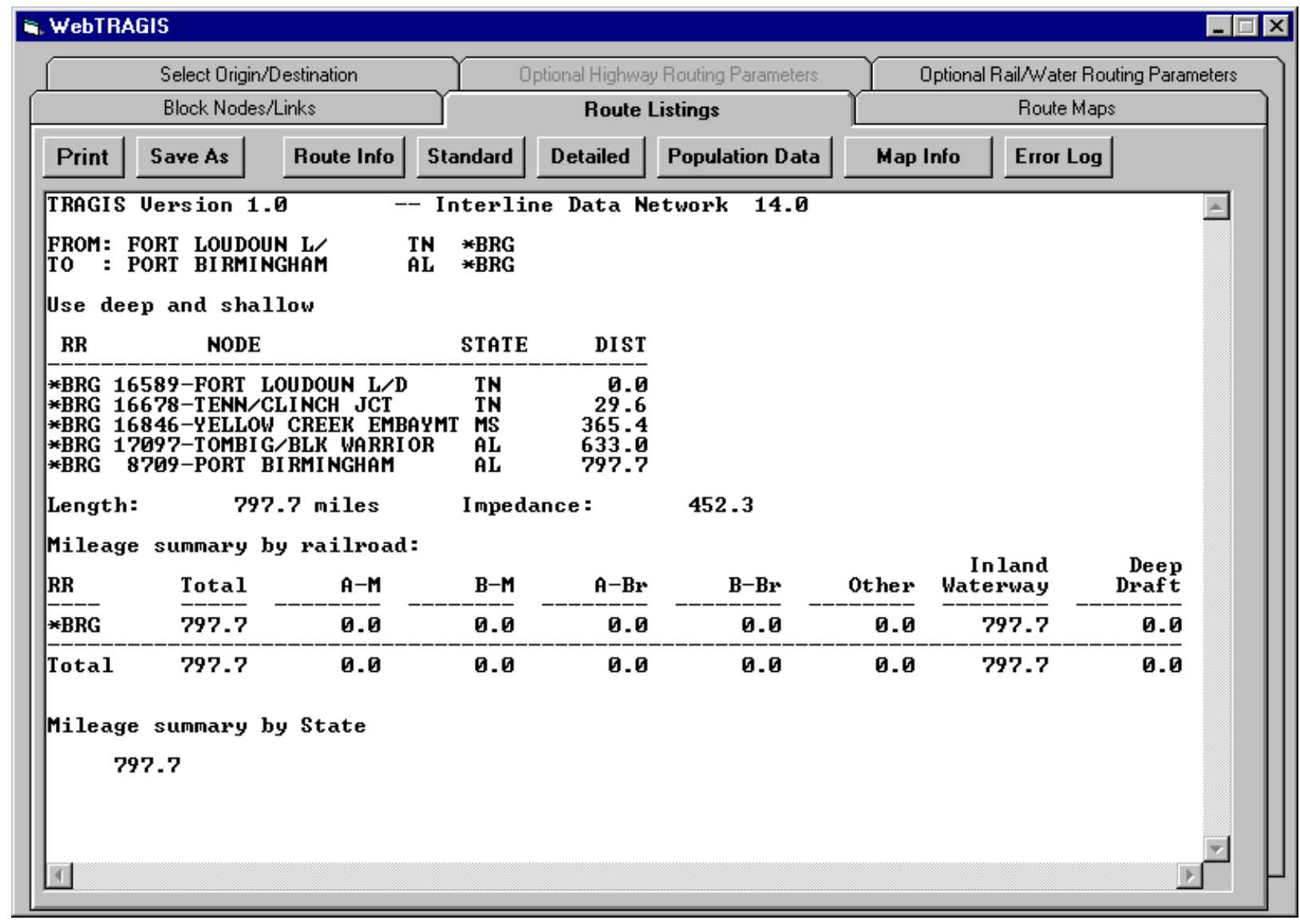

Fig. 5.2. Water-route listings.

The detailed listing provides much more information on the route. Every node on the route is listed along with information on link characteristics. Not every node in the database has a name, so node numbers are listed. Link information includes the link number; the distance of the link; the line classification code; a traffic volume code; a speed limit for freight trains; and, if the operating railroad is using trackage rights over this line, the abbreviation of the railroad owning the tracks. These items specific to railroad will be blank for water routes. As with the standard listing, summary information by subnetwork and state follows the route listing. 
The population-density information is viewed by clicking the Population Data button. A listing of the population density information for the route is displayed. The basic table includes 12 population-density categories ranging from 0 to over 9996 people per square mile. The entries in the table show the distance the route travels in each category. At the end of the table, summary information is provided for the route. This information combines the data from the 12 categories into rural, suburban, and urban groups and also provides a weighted populationdensity value for each of these groups. This information is used as input for routing risk analysis using the RADTRAN or RISKIND computer codes.

The final items on the Route Listings Tab are the Print and Save As button. When the Print button is clicked, the listing currently being viewed is sent to the printer. (Note: Be sure to display the desired information to the screen before printing). When the Save As button is clicked, a file selection dialog box is displayed. The file name and location can then be selected, and the listing currently being displayed is saved to that selected file.

\subsection{OPTIONAL RAIL/WATER ROUTING PARAMETERS TAB}

The Optional Rail/Water Routing Parameters tab provides access to a number of parameters that control the routing functions. When water is the active mode, Optional Rail/Water Routing Parameters tab is available, and the Optional Highway Routing Parameters tab is not.

When the Optional Rail/Water Routing Parameters tab is selected, a window of the water options is displayed. Figure 5.3 shows the water options window. Within this window, available options can be selected. Click on the item of interest to select them. The following sections discuss the various water options.

\subsubsection{Select Water Route Type}

The user can select the type of water route to be used, such as Deep Water route, Shallow Water route, or Both (deep and shallow).

\subsubsection{Modify Mode Transfer Penalty}

This allows the user to modify the transfer penalty from deep water to shallow water or the reverse. This is intended to cause the model to minimize the transfers similar to industry practice. The user selects the modes and enters the desired transfer penalty. (Note: This procedure is for experienced users only.) 


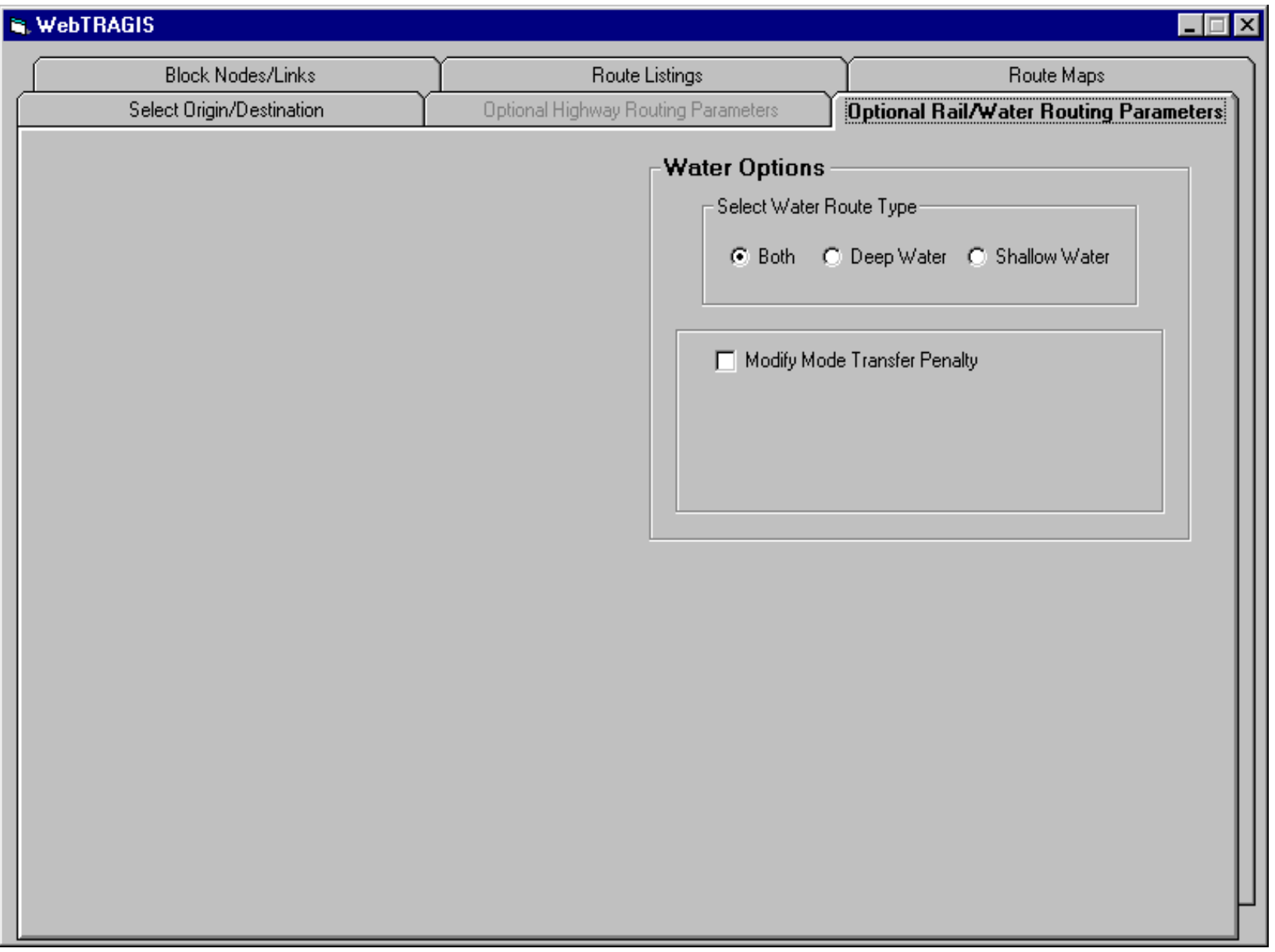

Fig. 5.3. Water options window.

\subsection{BLOCK NODES/LINKS TAB}

The Block Nodes/Links tab allows the user to block portions of the route database. These features can be useful when there is a need to analyze various scenarios. The Block

Nodes/Links tab has two grouping of commands. The first group involves blocking nodes. The second group involves blocking links. This window is shown in Fig. 5.4.

\subsubsection{Node Blocking}

Nodes can be blocked in the database by making all the links that emanate from the node ineligible for routing. To block a node, select the state in which the node exists. The Node Name list will be populated with node names for that state. Now select the node to be blocked by scrolling to the name and clicking on it. The node number will then appear in the Blocked Node Numbers list. 


\subsubsection{Link Blocking}

Since a link is defined by its nodes, you will be choosing the link by selecting its end points.

Block Links in the road database by first choosing the State. After a state is chosen, the Node1

Name list will be populated. The Node2 Name list will be populated will all of the nodes connected to Node1. Select Node2 from the list in Node2 Name list. The Blocked Link

Numbers list will now contain two entries, the first ending with a ' 1 ' and the second ending with $\mathrm{a}^{\text {' }}-1$ '. These block the link in both directions. If you want to block a link in only one direction, double click on the undesired entry and it will be removed from the list.

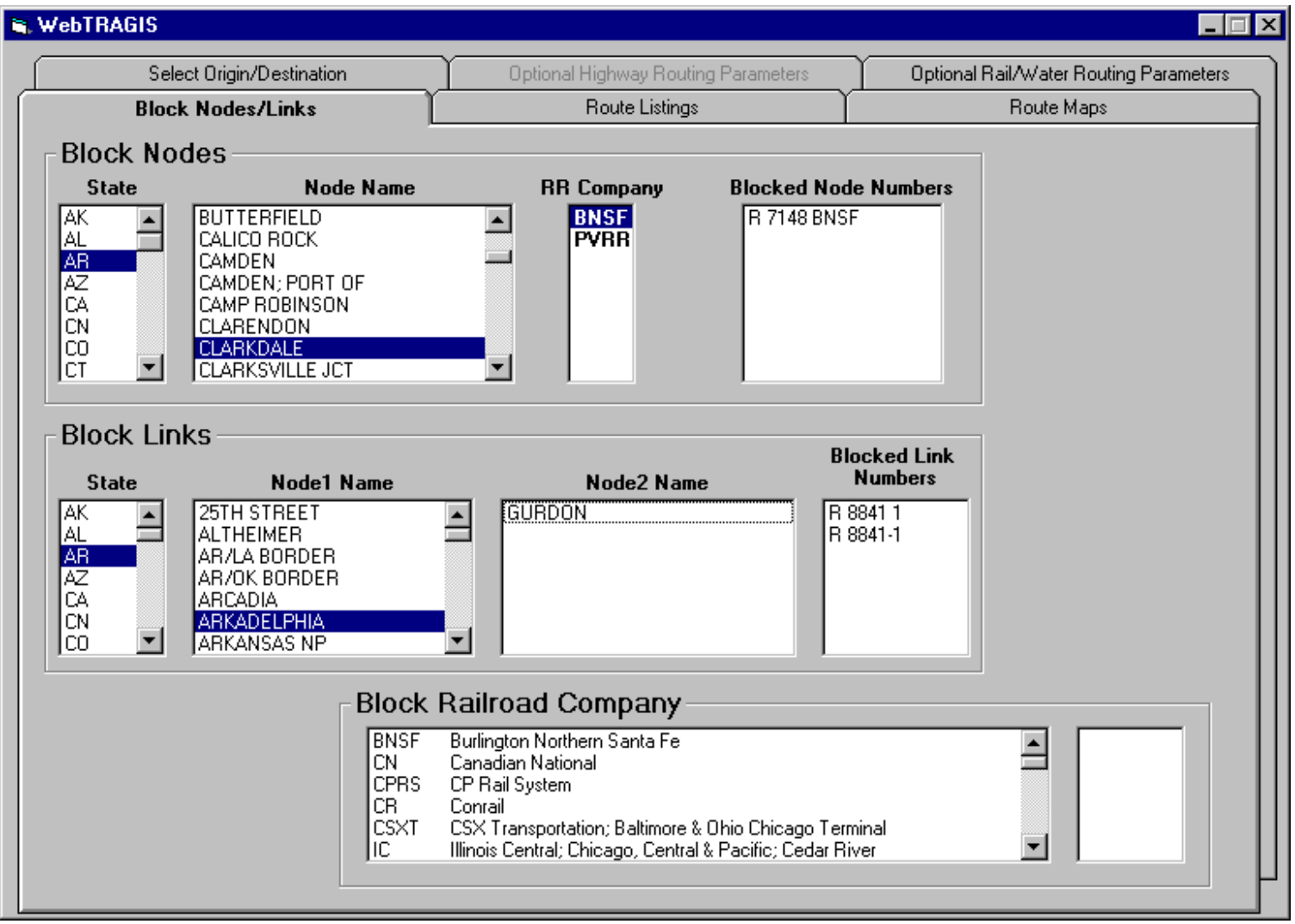

Fig. 5.4. Water node/link blocking. 


\section{ROUTE MAPS}

\subsection{BUTTON BAR ITEMS ON ROUTE MAPS TAB}

There are several buttons on the Route Maps tab. These buttons are useful for the mapping feature (Fig. 6.1). Each button has a popup box with a short description of its function and is described with more detail in the following sections.

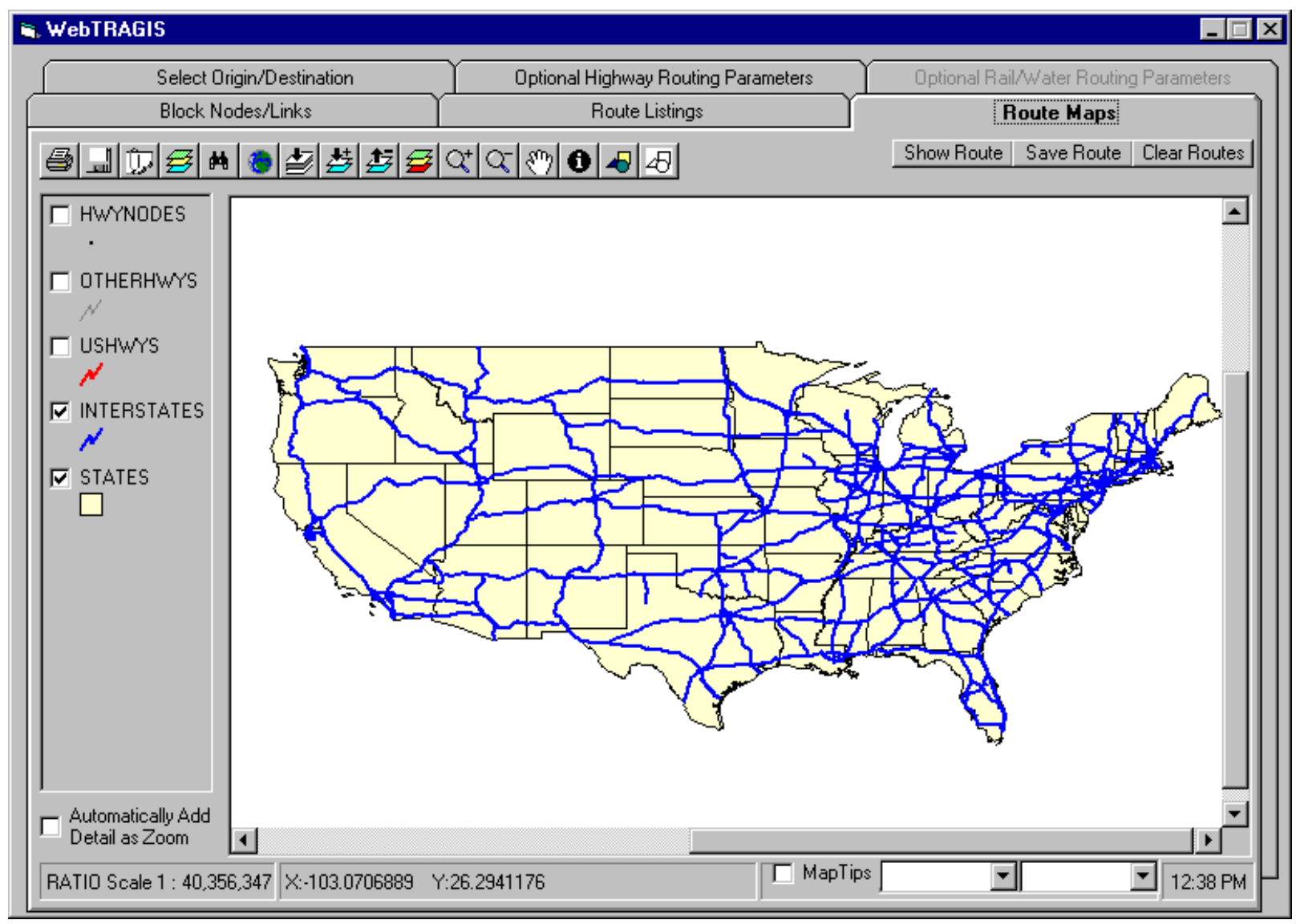

Fig. 6.1 Route maps.

\subsubsection{Print}

The Print button is symbolized by a icon of a printer. This button allows the printing of the current map display.

\subsubsection{Save As}

A floppy disk icon symbolizes the Save As button. This button allows saving the current map display as an enhanced windows metafile or as a bitmap file. The default is as an enhanced metafile because a metafile can be resized without appreciable loss of detail. This makes insertion of maps into a document easy. 


\subsubsection{Copy}

The Copy button is symbolized by a paper clip on a piece of paper. This button copies the currently displayed map onto the Windows clipboard, so it can be pasted into Windows applications.

\subsubsection{Map Properties}

Three-colored layers symbolize the Map Properties button. This button opens a window that allows the user to change properties of the map.

\subsubsection{Search}

The Search Map Information Files button is symbolized by a binocular. The maps have data elements associated with them, such as highway sign, speed limit, node names, etc. This button opens a window that allows the user to search these data elements.

\subsubsection{Display Full Extent of Map}

The Display Full Extent of Map button is symbolized by a globe. This button zooms out to fill the map display with the entire map.

\subsubsection{Display Map to Extent of Active Layer}

The Display Map to Extent of Active Layer button is symbolized by an arrow pointing into three gray layers. This button zooms out to fill the map display with the current layer data.

\subsubsection{Add Map Layer}

The Add Map Layer button is symbolized by an arrow pointing into colored layers with a plus sign. This is usually used to display a route that was saved earlier. Click this button, and a file selection dialog box will allow the selection of a map layer to display.

\subsubsection{Remove Active Map Layer}

The Remove Active Map Layer button is symbolized by an arrow pointing out of colored layers with a minus sign. Choose a map layer by clicking on the title of the map layer in the legend, and then click this button to delete layer from the map.

\subsubsection{Modify Map Layer Properties}

The Modify Map Layer Properties button is symbolized by colored layers with green, yellow, and red layers. This button opens a window to allow the user to modify the properties of the current map layer. The current layer is denoted by an outline on the legend. 


\subsubsection{Zoom In}

The Zoom In button is symbolized by a magnifying glass containing a plus sign. This tool is used to zoom in or to enlarge an area within the display. To perform a zoom in, choose the zoom in tool so that the button icon appears depressed. When moving the pointing device over the display window, the pointer icon appears as the magnifying glass with a plus sign in it. Position the pointing device at a corner of the area desired to be enlarged while holding down the left mouse button. Move the pointer to the opposite corner of the desired area and release. The display window is redrawn.

\subsubsection{Zoom Out}

The Zoom Out tool is symbolized by a magnifying glass containing a minus sign. This tool is used to show a larger geographic area in the display. To zoom out, use the left mouse button to choose the Zoom Out button. The Zoom Out tool functions in a way opposite that of the zoom in tool. If the click-and-drag method is used, the smaller the area that is defined, the more area will be displayed after the zoom out.

\subsubsection{Pan}

A hand symbolizes the Pan tool item. This tool will pan or drag the display in the direction the cursor is moved in order to reposition the map within the window. As with other tools, first choose the Pan tool and then move the pointer over the display window. The pointer will be displayed as a hand. Hold the left mouse button down and drag the display within the window.

\subsubsection{Identify}

The Identify tool button has a lowercase I inside a black circle. This tool is used to display information about features in the map display. To use this tool, first choose the identity tool in the tool bar. Next, examine the legend box to determine which theme is currently highlighted (the item that appears to have a highlight box around it). To change the highlighted theme, move the pointer over the theme name and click either the left or right mouse button. Now click on a feature in the display, and an identity-results window will appear which lists all the attribute variables and their values for that feature. To remove the identity-results window, move the pointer over the title bar of this window and press the $\mathbf{X}$ button.

\subsubsection{Add Graphics to Map}

Colored geometric shapes symbolize the Add Graphics to Map button. This tool allows the user to draw dots, straight lines, multiple-point lines, rectangles, circles, and polygons. To select the appropriate item, press the Add Graphics to Map button. A new tool bar will appear showing icons for the different features available. After selecting a type of feature to draw, the symbol can be drawn. The technique used for each type of draw tool varies; either click at one spot (to locate a dot); multiple spots with a double-click to end (to draw lines, rectangles, and polygons); or click, hold, move, and release (to draw circles). 


\subsubsection{Remove Graphics}

Gray geometric shapes symbolize the Remove Graphics button. The Remove Graphics tool is the right-most item on the tool bar. Clicking this button will remove all graphics added to the map with the Insert Graphics button.

\subsection{SHOW ROUTE}

Depressing the Show Route button converts the data from the last route calculated and displays the route on the map.

\subsection{SAVE ROUTE}

The Save Route button saves the last route calculated in the map layer format so that the route can be displayed later using the Add Map Layer. This is useful when it is desired to display several routes on a single map.

\subsection{CLEAR ROUTES}

Depressing the Clear Routes button clears all routes from the displayed map.

\subsection{OTHER ITEMS}

At the bottom of the map is a status bar. The first item displays the scale at which the map is currently displayed. The second item displayed the X, Y coordinates of the map cursor. The display is in decimal degrees.

The third item contains a check box titled "MapTips" and two drop down lists. Checking this box will display information associated with the map available for display. The first drop-down list shows the map layers. The second drop-down list shows the data elements available for the map layer selected by the first drop-down list. Select the desired map layer in the first dropdown list. Next select the desired data item from the second drop-down list; then hold the cursor still over the map feature. After a second or so, a box will appear showing the data item related to that map feature.

The fourth item displays the computer's clock. 


\section{CONCLUSION}

WebTRAGIS provides a major change in technology from the earlier routing models developed at ORNL. The HIGHWAY and INTERLINE models were developed at a time when text based programs were the standard form. Additional improvements will be made to WebTRAGIS to improve and enhance the performance of the model. 


\section{REFERENCES}

1. Johnson, P. E.; Joy, D. S.; Clarke, D. B.; Jacobi, J. M., HIGHWAY 3.1-An Enhanced Highway Routing Model: Program Description, Methodology, and Revised User's Manual, ORNL/TM-12124, March 1993.

2. Johnson, P. E.; Joy, D. S.; Clarke, D. B.; Jacobi, J. M., INTERLINE 5.0-An Expanded Railroad Routing Model: Program Description, Methodology, and Revised User's Manual, ORNL/TM-12090, March 1993.

3. Neuhauser, K. S.; Kanipe, F. L., RADTRAN 4: Volume 3, Users Guide, SAND89-2370, January 1992.

4. Yuan, Y.C.; Chen, S.Y.; Biwer, B.M.; LePoire, D.J., RISKIND—A Computer Program for Calculating Radiological Consequences and Health Risks from Transportation of Spent Nuclear Fuel, ANL/EAD-1, November 1995. 